\title{
8-Hydroxyquinolines: a review of their metal chelating properties and medicinal applications
}

This article was published in the following Dove Press journal:

Drug Design, Development and Therapy

3 October 2013

Number of times this article has been viewed

\author{
Veda Prachayasittikul' \\ Supaluk Prachayasittikul ${ }^{2}$ \\ Somsak Ruchirawat ${ }^{3}$ \\ Virapong Prachayasittikul' \\ 'Department of Clinical Microbiology \\ and Applied Technology, Faculty of \\ Medical Technology, ${ }^{2}$ Center of Data \\ Mining and Biomedical Informatics, \\ Faculty of Medical Technology, \\ Mahidol University, Bangkok, Thailand; \\ ${ }^{3}$ Laboratory of Medicinal Chemistry, \\ Chulabhorn Research Institute and \\ Chulabhorn Graduate Institute, \\ Bangkok, Thailand
}

\section{Video abstract}

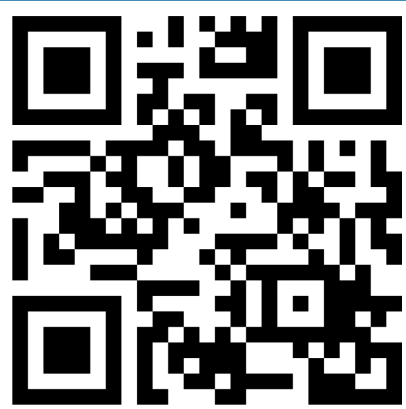

Point your SmartPhone at the code above. If you have a $Q R$ code reader the video abstract will appear. Or use: http://dvpr.es/15va] 67

Correspondence: Virapong Prachayasittikul

Department of Clinical Microbiology and Applied Technology, Faculty of Medical

Technology, Mahidol University,

999 Phutthamonthon 4 Road

Salaya, Phutthamonthon, Nakhon Pathom

73170 , Thailand

Tel +66 244I 4376

Fax +66 244I 4380

Email virapong.pra@mahidol.ac.th
Abstract: Metal ions play an important role in biological processes and in metal homeostasis. Metal imbalance is the leading cause for many neurodegenerative diseases such as Alzheimer's disease, Parkinson's disease, and multiple sclerosis. 8-Hydroxyquinoline (8HQ) is a small planar molecule with a lipophilic effect and a metal chelating ability. As a result, 8HQ and its derivatives hold medicinal properties such as antineurodegenerative, anticancer, antioxidant, antimicrobial, anti-inflammatory, and antidiabetic activities. Herein, diverse bioactivities of 8HQ and newly synthesized 8HQ-based compounds are discussed together with their mechanisms of actions and structure-activity relationships.

Keywords: metal binding compound, antineurodegenerative, anticancer, antidiabetic, multifunctional actions, structure-activity relationships

\section{Introduction}

8-Hydroxyquinoline (8HQ) (Figure 1), a quinoline derivative originating in plants as well as from synthesis, has been used as a fungicide in agriculture and a preservative in the textile, wood, and paper industries. ${ }^{1} 8 \mathrm{HQ}$ possesses potent coordinating ability and good metal recognition properties, which means it is widely used for analytical and separation purposes as well as for metal chelation. ${ }^{2}$

Metal ions play a very important role in biological processes, and metal homeostasis is required for the maintenance of metal balance. ${ }^{3,4}$ Many diseases arise from the loss of homeostasis including metal overload and deficiency, which are caused by abnormal metal metabolism or metal absorption. Of all the hydroxyquinoline derivatives, $8 \mathrm{HQ}$ is the most interesting one to be explored, owing to its multifunctional properties, such as diverse bioactivities and therapeutic potentials. ${ }^{5}$

$8 \mathrm{HQ}$ is the only one, among seven isomeric monohydroxyquinolines, capable of forming complexes with divalent metal ions through chelation. ${ }^{6}$ Most bioactivities of $8 \mathrm{HQ}$ and its derivatives originate from their chelating ability. As previously mentioned, metal imbalance is the leading cause for many diseases, therefore, $8 \mathrm{HQ}$ is a potent chelator that may restore metal balance and be useful for the treatment of metal-related diseases. In this review, the bioactivities, mechanisms of actions of newly synthesized 8HQ-based compounds, and their structure-activity relationships (SAR) will be discussed.

\section{Antineurodegenerative activity}

Transition metals such as $\mathrm{Fe}, \mathrm{Zn}$ and $\mathrm{Cu}$ are found in the brain at relatively high concentration and are required for the brain's cellular processes including synaptic neuronal 


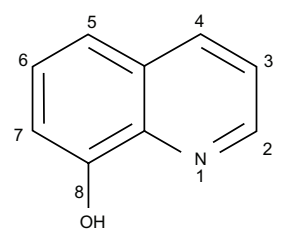

Figure I Structure of 8-hydroxyquinoline.

activity and metalloenzyme function; for instance, $\mathrm{Cu} / \mathrm{Zn}$ superoxide dismutase (SOD), cytochrome $\mathrm{C}$ oxidase, etc. ${ }^{3}$

Metal homeostasis dysregulation is generally accepted as a key predisposing factor in many neurodegenerative diseases such as Alzheimer's disease (AD), Parkinson's disease, multiple sclerosis and others. ${ }^{4,7}$ Increasing levels of redox-reactive metal ions, such as $\mathrm{Cu}$ and $\mathrm{Fe}$, in specific brain regions can generate reactive oxygen species (ROS) that cause lipid peroxidation and toxic reactive aldehyde products. These finally lead to damage of cellular components. ${ }^{7}$ The proteasome is a cellular system that degrades unwanted or abnormal proteins. ${ }^{4}$ It is worth noting that metal ions can interact with proteins in the brain and induce their conformational change, leading to protein misfolding and rendering them resistant to proteasomes. Moreover, metal-protein interaction facilitates aggregation and accumulation of misfolded proteins in regions of the brain, ${ }^{8}$ leading to neurotoxicity, neuronal dysfunction, and neuronal cell death. ${ }^{7,9}$ It has been suggested that dysregulation of metal homeostasis and metal ion-protein interactions are involved in the pathogenesis of neurodegenerative diseases. ${ }^{10-12}$ Therefore, metal chelation therapy has been proposed to be a promising approach in restoring metal balance and reducing neurotoxicity caused by metal-protein interaction. ${ }^{13}$

An ideal metal chelator for neurodegenerative treatment had been suggested to be a low molecular weight (MW) and lipophilic (uncharged) compound capable of crossing the blood-brain barrier to reach target sites in the brain. ${ }^{3}$ In addition, the selectivity of compounds in chelating certain metal ions but not affecting metalloenzymes would also be required for cellular functions. ${ }^{3}$ It is necessary that the compound would be able to chelate metal ions in accumulated proteins $^{3}$ in order to reverse proteasome resistance, thereby allowing misfolded proteins to be degraded..$^{14}$ Moreover, the drug itself is required to have minimal toxicity and side effects. ${ }^{3}$ However, merely controlling misfolded protein levels may not be sufficient to reverse the neurodegenerative progression in the brain. ${ }^{14}$ Therefore, a new therapeutic strategy for preventing metal-protein interaction has been recently proposed. ${ }^{14}$

A series of $8 \mathrm{HQ}$ derivatives, such as 5-chloro-7-iod o-8-hydroxyquinoline, or clioquinol (CQ), 5-((4-(prop2-ynyl)piperazin-1-yl)methyl)quinolin-8-ol (HLA-20), 5-((methyl(prop-2-ynyl)amino)methyl)quinolin-8-ol (M30), and 5-((4-(2-hydroxyethyl)piperazin-1-yl)methyl)quinolin8-ol (VK-28) (Figure 2), have been reported to exert potent antineurodegenerative effects. ${ }^{15}$ Among these, CQ has reached pilot Phase II of clinical trials in $\mathrm{AD}$ patients. ${ }^{16-20}$

CQ was originally used as an antimicrobial for amoebic dysentery (traveler's diarrhea); however, after its neurotoxicity was reported among the Japanese in the late 1960s, this drug was withdrawn from oral usage..$^{21}$ The proposed mechanism of toxicity is that CQ decreases vitamin B12 bioavailability, which results in neurological symptoms. ${ }^{22}$ However, the neurotoxicity can be reversed by vitamin supplementation and dosage control. ${ }^{20}$

CQ is a potent chelator containing two electron donor sites located at the quinoline ring nitrogen atom and phenolate oxygen atom, which give rise to its chelating ability (Figure 3A). Moreover, halogen groups are known to increase its lipophilicity to allow its absorption to target sites in the brain. ${ }^{9} \mathrm{CQ}$ selectively chelates $\mathrm{Cu}$ and $\mathrm{Zn}$ ions, ${ }^{9,23}$ which play<smiles>Oc1c(I)cc(Cl)c2cccnc12</smiles>

Clioquinol (CQ)

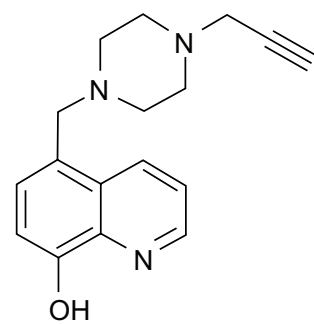

HLA-20<smiles>C#CCN(C)Cc1ccc(O)c2ncccc12</smiles>

M30

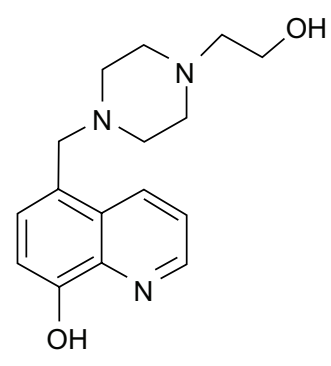

VK-28

Figure 2 8-Hydroxyquinoline derivatives with potent antineurodegenerative activity.

Abbreviations: HLA-20, 5-((4-(prop-2-ynyl)piperazin-I-yl)methyl)quinolin-8-ol; M30, 5-((methyl(prop-2-ynyl)amino)methyl)quinolin-8-ol; VK-28, 5-((4-(2-hydroxyethyl) piperazin- I-yl)methyl)quinolin-8-ol. 
a vital role in misfolded protein production, aggregation, and accumulation that ultimately leads to neurotoxicity in AD. ${ }^{9,24}$ However, the selectivity of the compound can minimize the chance of developing a depletion in systemic metal ions. ${ }^{9}$

Recently, a dual mechanism of CQ action based on metalprotein interaction has been proposed. ${ }^{14}$ Firstly, as $\mathrm{Cu}$ and Zn chelators, CQ can inhibit misfolded protein production and aggregation. Moreover, the chelation of accumulated $\mathrm{Zn}$ in misfolded proteins can reverse proteasome resistance and promote misfolded protein degradation. ${ }^{14}$ However, the affinity of the compound to chelate $\mathrm{Zn}$ is not enough to alter Zn metalloenzymes. ${ }^{14}$ Secondly, CQ can function as a metal chaperone in transporting metal ions into cells and promoting redistribution of ions that consequently activate cell signaling involved in neuroprotective cascades. ${ }^{25}$ Thus, the activity of CQ can be attributed to two aspects: the prevention of neurotoxicity initiated by metal-protein interaction and the redistribution of metal ions into cells to promote protective functions. ${ }^{14}$ It has been reported that CQ is a potent antineurodegenerative agent that can improve cognitive functions in $\mathrm{AD}$ patients; ${ }^{3}$ however, this compound was not further developed owing to manufacturing difficulties. This was due to the presence of a small amount of the carcinogenic contaminant 5,7-diiodo-8-hydroxyquinoline (Figure 3B) that forms during large-scale chemical synthesis. ${ }^{14}$ Thus, PBT2, a second generation CQ, was developed to solve the problem of CQ and to improve its solubility and its ability to cross the blood-brain barrier. ${ }^{14}$ It was observed that PBT2 could selectively chelate $\mathrm{Cu}$ and $\mathrm{Zn}$ and form neutral soluble complexes capable of passing through cellular membranes. Due to its moderate affinity to metal ions, after entering cells it can release metal ions from the complex. This leads to bioavailable delivery of $\mathrm{Cu}$ and $\mathrm{Zn}$ into cells. ${ }^{26-28}$ So far, PBT2 has shown improvement of cognitive function as noted for CQ in Phase IIa of clinical trials in AD patients. ${ }^{29,30}$ Results supported by in vitro and in vivo studies suggested that antineurodegenerative efficacies of both CQ and PBT2 are based on their chelating ability and metal ion

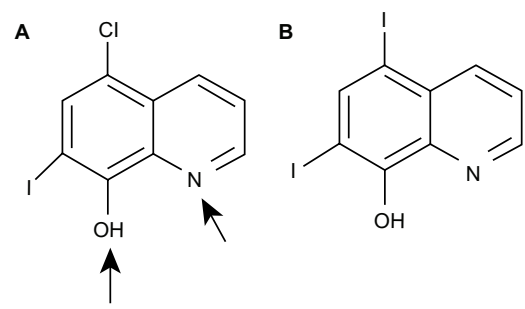

Figure 3 Clioquinol and its electron donor sites (A) and 5,7-diiodo-8hydroxyquinoline (B). delivery into cells. ${ }^{26-28}$ Moreover, metal binding affinity of both compounds is high enough to inhibit misfolded protein production and aggregation but not high enough to alter the actions of metalloenzymes. ${ }^{27,31}$

The Fe ion is considered to be another redox-reactive metal ion that causes oxidative stress via the Fenton reaction. It is found to be elevated in many neurodegenerative diseases, such as AD, ${ }^{3}$ Parkinson's disease, ${ }^{32}$ and amyotrophic lateral sclerosis. ${ }^{33}$ In view of its multifunctional roles, 8HQ-based compounds have been utilized in the treatment and improvement of neurodegenerative patients. For example, M30 and HLA-20 (Figure 4) are novel multifunctional $8 \mathrm{HQ}$-based drugs synthesized by combining an Fe chelating compound possessing an antioxidant activity (VK-28) with the Parkinson's drug (Ladostigil) containing the N-propagylamine moiety (Figure 5), which affords the neuroprotective property. ${ }^{34}$

As outlined in Figure 6, VK-28 can chelate excessive Fe ions in the brain, thereby preventing the Fenton reaction that produces reactive hydroxyl radicals $(\mathrm{OH})$. It is capable of directly scavenging $\mathrm{OH}$, which gives rise to antioxidant effects. ${ }^{35,36}$ Ladostigil contains the propargylamine moiety that accounts for its inhibition of the monoamine oxidase enzyme. ${ }^{34}$ This enzyme is involved in dopamine oxidation, which generates hydrogen peroxide $\left(\mathrm{H}_{2} \mathrm{O}_{2}\right)$ that initiates the Fenton reaction in the presence of $\mathrm{Fe}^{2+}$, leading to oxidative stress in neurons. ${ }^{32}$ Compounds M30 and HLA-20 have moderate chelating affinity toward $\mathrm{Fe}, \mathrm{Cu}$, and, $\mathrm{Zn}$, with the order $\mathrm{Fe}^{3+}>\mathrm{Cu}^{2+}>\mathrm{Zn}^{2+}$, and they strongly inhibit mitochondrial membrane peroxidation in vitro with a half maximal inhibitory concentration $\left(\mathrm{IC}_{50}\right)$ in the micromolar range. ${ }^{15,37}$ In vitro studies indicated that M30 upregulates expression of $\mathrm{Fe} / \mathrm{O}_{2}^{-}$regulated hypoxia inducible factor, which is a hypoxia mimetic regulator, resulting in neuronal prosurvival and cytoprotective effects. ${ }^{38-40}$ In addition, M30 has been reported to exhibit neurorescue and neuroprotective activities in animal models. ${ }^{41}$

Therefore, both HLA-20 and M30 are novel multifunctional drugs that exhibit promising antioxidant and neuroprotective effects as well as antidepressant activity. These bioactivities arise from the ability of the compounds to elevate levels of dopamine, serotonin, and norepinephrine in the brain through the inhibition of the monoamine oxidase enzyme. ${ }^{42}$

\section{Anticancer activity}

It has been well recognized that redox-active metal ions do not only play important roles in normal cells but are also 

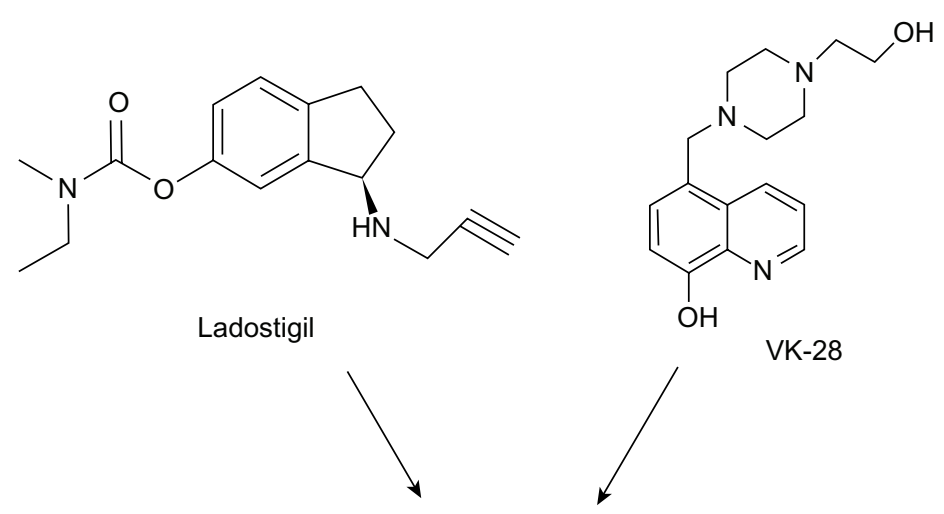

VK-28

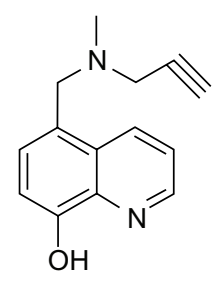

M30

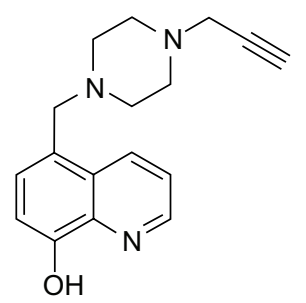

HLA-20

Figure 4 M30 and HLA-20 are hybrids of Ladostigil and VK-28.

Abbreviations: HLA-20, 5-((4-(prop-2-ynyl)piperazin-I-yl)methyl)quinolin-8-ol; M30, 5-((methyl(prop-2-ynyl)amino)methyl)quinolin-8-ol; VK-28, 5-((4-(2-hydroxyethyl) piperazin- |-y|)methyl)quinolin-8-ol.

essential in cancer cells. Some transition metal ions, such as $\mathrm{Fe}$ and $\mathrm{Cu}$ are considered as cancer risk factors. ${ }^{43-50}$

In normal cells, Fe serves as a prosthetic group in many enzymes that are required for physiological processes, such as oxidase, catalase, and ribonucleotide reductase. In contrast, it generates ROS, leading to lipid peroxidation and damage to cellular components, such as lipids, proteins, and DNA. ${ }^{51,52}$ Thus, Fe plays essential roles in cancer via the generation of ROS as well as serving as a nutrient for the growth of cancer cells. $^{43}$

Most Fe that exists in the human body is in the proteinbound form that cannot promote lipid peroxidation or ROS formation. ${ }^{51}$ In addition, free Fe per se is a poor catalyst for reactive oxygen metabolites, but Fe toxicity arises when it binds to a low-MW chelator. Therefore, the formed Fe-chelator complex causes the dissociation of $\mathrm{H}_{2} \mathrm{O}_{2}$ into $\mathrm{OH} .{ }^{53}$ The chelating ability of 8HQ has been proposed to account for its observed cytotoxic activity as afforded by the Fe-8HQ complex. ${ }^{54}$

The formed Fe-8HQ lipophilic complex is capable of entering and being distributed within cells, ${ }^{55}$ causing massive

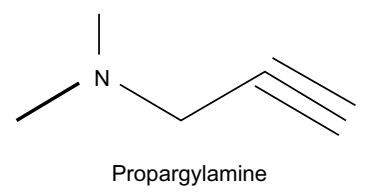

Figure 5 Propargylamine moiety. breakage of DNA strands. In order to repair damaged DNA, large quantities of adenosine triphosphate are required, which consequently leads to cellular adenosine triphosphate depletion and finally cell death. ${ }^{56}$ As such, possible mechanisms of DNA damage were proposed. The Fe-8HQ complex may be formed at specific sites that break the phosphodiester backbone of DNA, acting as chemical nucleases, causing oxidative degradation at the deoxyribose moiety. ${ }^{57}$ In other words, the Fe-8HQ complex acts as a cytostatic drug. ${ }^{58}$ Another possible mechanism is that the Fe-chelator complex induces membrane damage, that leads to loss of calcium homeostasis, which triggers endonuclease to cleave DNA in an apoptotic-like manner. ${ }^{54}$ Results from SAR studies demonstrated that 8HQ is a crucial scaffold for anticancer activity. ${ }^{59}$ This relationship is derived from the ability of the compound to form chelate complexes with metal ions, incorporated with essential enzymes for DNA synthesis, ${ }^{60}$ possibly, ribonucleotide reductase. ${ }^{61}$ Moreover, bis-type structure of $8 \mathrm{HQ}$ is required for potent anticancer activity. ${ }^{62}$ In fact, $\mathrm{S}_{1}$ [bis-N-(8HQ-5-ylmethyl)benzylamine] has been reported to form Fe complexes with higher affinity to exert higher antiproliferative effects as compared to o-trensox (ie, the reference drug). However, o-trensox is a very high affinity $\mathrm{Fe}$ chelator in hepatocyte cultures. ${ }^{60}$ The results indicated that $\mathrm{S}_{1}$ is a promising starting point for anticancer drug development. ${ }^{60}$ In addition, metal complexes of mixed 


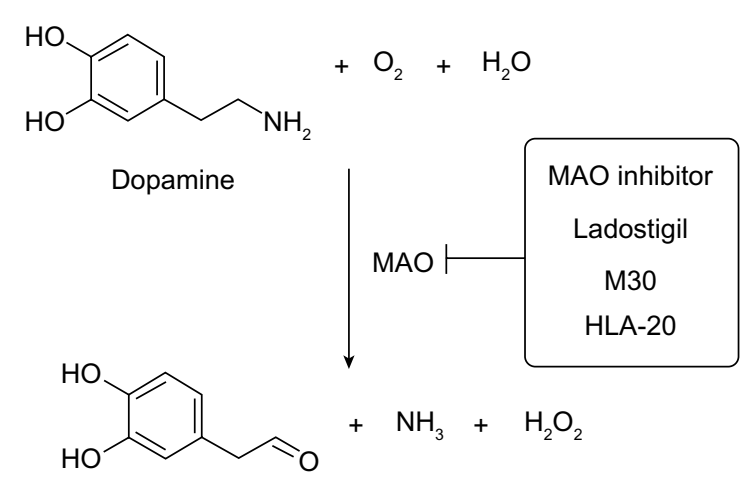

3,4-dihydroxylphenylacetylaldehyde

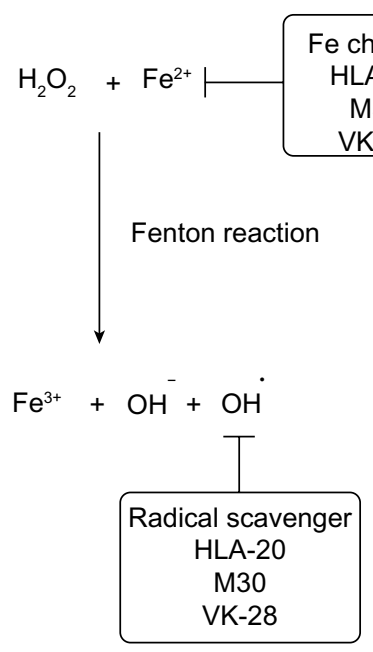

Figure 6 Metabolism of dopamine and actions of 8-hydroxyquinoline derivatives.

Abbreviations: HLA-20, 5-((4-(prop-2-ynyl)piperazin-I-yl)methyl)quinolin-8-ol; M30, 5-((methyl(prop-2-ynyl)amino)methyl)quinolin-8-ol; VK-28, 5-((4-(2-hydroxyethyl) piperazin-I-yl)methyl)quinolin-8-ol; MAO, monoamine oxidase enzyme; $\mathrm{OH}$, reactive hydroxyl radical.

ligands of 8HQ-uracils (Figure 7) have been reported to provide significant cytotoxicity against human cancer cells (ie, HepG2, A549, HuCCA-1, and MOLT-3). ${ }^{63}$

Recently, great interest in metal complex compounds has extensively increased due to their wide range of applications. ${ }^{64}$ The interaction of metal complexes with DNA has been studied for biotechnology and medical applications including their use as anticancer drugs. ${ }^{65}$ The metal complex binds reversibly to DNA via noncovalent interactions, such as electrostatic binding, groove binding, and intercalative binding. ${ }^{66,67}$ Intercalation between metal complexes and DNA bases is considered to be the most important binding mode giving rise to antitumor activity. ${ }^{68}$ This causes DNA conformational changes, which finally leads to DNA strand stress and breakage. ${ }^{69}$

The intercalating ability of metal complex compounds are dependent on the planarity of the ligands, the coordination geometry, types of ligand donor atoms, and metal ions. ${ }^{70}$ Sulfonamide-substituted 8HQ metal complexes have been reported to exhibit higher DNA binding affinity than that of free ligands. ${ }^{69}$ The highest binding efficiency among metal complexes that are formed using the same ligands was found to be that of $\mathrm{Cu}$ complexes. ${ }^{69}$ It was suggested that pharmacological activities of metal complexes are dependent on the nature of both the ligands and the metal ions. ${ }^{71}$ This notion was demonstrated for metal complexes synthesized from different types of metal ions using the same ligand; such metal complexes were found to exert different bioactivities. $^{72,73}$

$\mathrm{Cu}$ ions are a risk factor predisposing to cancer, and they also serve as an essential cofactor for tumor angiogenesis, that is crucial for tumor growth and metastasis. ${ }^{44-47}$ High levels of $\mathrm{Cu}$ in tissue or serum has been found in many cancer patients including those with breast, prostate, colon, lung, and brain cancer. $^{74-78}$ It was suggested that $\mathrm{Cu}$ could be used as one of the selective targets for cancer treatments. ${ }^{79}$

The anticancer effects of 8HQ derivatives, such as CQ, are related to $\mathrm{Cu}$ and $\mathrm{Zn}$ ions. $\mathrm{As}$ a $\mathrm{Cu}$ chelator, $\mathrm{CQ}$ exerts selective antiangiogenesis activity ${ }^{80}$ toward breast cancer ${ }^{81}$, prostate cancer, ${ }^{79}$ leukemia, and myeloma, ${ }^{82}$ with less effect on normal cells. In addition, the antitumor activity of CQ has been proposed to be tightly associated with proteasome inhibitory ability, ${ }^{79}$ which is elicited through ionophore actions.

Ionophore is a subset of metal-binding drugs that are capable of transferring multiple metal ions across biological membranes, either in or out of cells. ${ }^{83-85}$ Two properties are required for metal-binding compounds to act as ionophore,
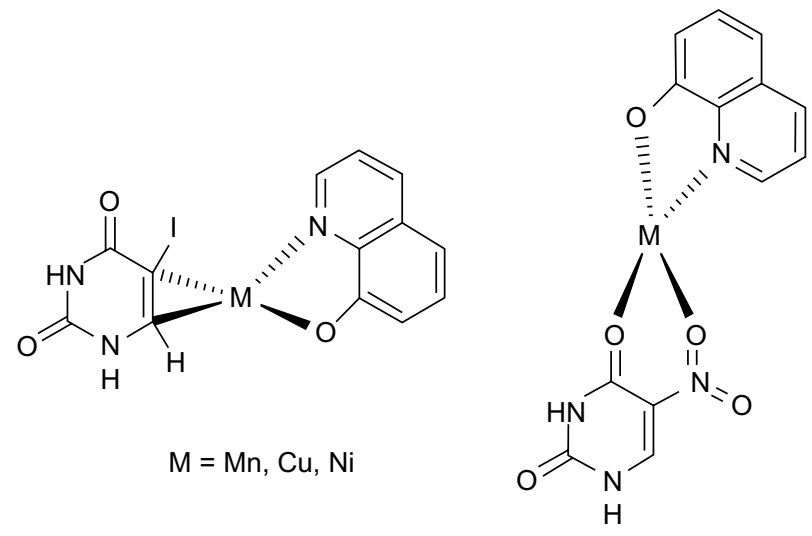

Figure 7 Structure of 8-hydroxyquinoline-uracil metal complexes. 
which are described as follows. First, compounds should have low to moderate metal affinity, allowing them to bind metal ions in higher concentration areas and release them in lower concentration areas. ${ }^{80}$ Second, a suitable logarithmic measure of acid dissociation constant value $(\mathrm{pKa})$ is necessary for compounds to be protonated upon entering cell compartments, which induces the release of metal ions from the complex. ${ }^{80}$ If the extracellular $\mathrm{pH}$ is higher than the $\mathrm{pKa}$ of the ionophore, the compound will form a complex with the metal ion. Once the metal complex passes into the cell, where the $\mathrm{pH}$ is lower than the $\mathrm{pKa}$, the metal ions will be released. ${ }^{80}$ Both properties have been noted for CQ thereby allowing it to act as an ionophore with the capability to transport $\mathrm{Cu}$ and $\mathrm{Zn}$ ions into cells. ${ }^{25,26,86}$

As a $\mathrm{Cu}$ ionophore, $\mathrm{CQ}$ has been reported to be able to deliver metal ions into cells, where it exerts its activity. ${ }^{79}$ $\mathrm{CQ}$ has been found to interact with $\mathrm{Cu}$ ions in tumor cells to form active $\mathrm{Cu}$ complexes which target the proteasome. ${ }^{87}$ Either $\mathrm{Cu}^{1+}$ or $\mathrm{Cu}^{2+}$ interact with electron donors, such as thiol and amino groups that are located outside the active site of proteasome ${ }^{88-90}$ thereby causing its conformational changes. These effects finally lead to proteasome inhibition ${ }^{79,87}$ and apoptosis of tumor cells. ${ }^{87}$ Some organic $\mathrm{Cu}$ complexes including CQ-Cu complexes have been reported to exhibit potent proteasome inhibitory effects on tumor cells but not on normal cells. ${ }^{81,91}$ Moreover, in vivo study of the effect on prostate cancer cells and xenografts by CQ was reported. ${ }^{79}$ The results showed that CQ alone can form an active metal complex with $\mathrm{Cu}$ of tumor cells, leading to androgen receptor repression, angiogenesis reduction, and apoptosis induction. Particularly, androgen receptor overexpression was found in all stages of prostate cancer, ${ }^{92,93}$ indicating that CQ may serve as an excellent antiandrogen receptor agent for prostate cancer treatment and prevention. ${ }^{79}$

Besides acting as the $\mathrm{Cu}$ ionophore, $\mathrm{CQ}$ also provides anticancer activity as the $\mathrm{Zn}$ ionophore. ${ }^{84}$ The CQ-Zn complex is a known proteasome inhibitor; however, its growth inhibitory effect is weaker than that exerted by the CQ-Cu complex. ${ }^{84}$ In addition, CQ relays $\mathrm{Zn}$ ions to lysosomes ${ }^{85}$ and inhibits nuclear factor kappa-light-chain-enhancer of activated B cells (NF- $\mathrm{BB}$ ) activity ${ }^{84,94}$ thereby leading to lysosomal disruption and cell apoptosis. ${ }^{84,95}$

The ionophore property of CQ was confirmed by adding metal ions, such as $\mathrm{Cu}$ and $\mathrm{Zn}$, which can potentiate its cytotoxic activity instead of reversing the effects, as can be expected in the case of metal chelators. ${ }^{80}$ This indicated that CQ can transport metal ions into cells and exhibits cytotoxic activity. ${ }^{80}$ Furthermore, the anticancer activity of $8 \mathrm{HQ}$ derivatives on human cancer cells indicated that the effect is enhanced by $\mathrm{Cu}$ ions, a redox-reactive metal ion, as it leads to an elevation of ROS. However, such effects were not observed for $\mathrm{Zn}$ ions, which are non-redox reactive metal ions. ${ }^{96}$

It has been further demonstrated that nitro containing 8 HQ derivatives such as nitroxoline (8-hydroxy-5-nitroquinoline; NQ) (Figure 8) exerted more potent anticancer activity, with a $\mathrm{IC}_{50}$ of 5-10-fold less than that of CQ (halogenated 8 HQ derivative), and may be less neurotoxic. ${ }^{96}$ Unlike $\mathrm{CQ}$, the antitumor effect of NQ is mainly exhibited via an increasing level of ROS in cells. The nitro moiety of NQ is a nitrogen radical source that initiates redox reactions, that consequently alters intracellular signaling thereby leading to antiangiogenesis and inhibition of tumor cell growth. These effects are enhanced by $\mathrm{Cu}$ but not $\mathrm{Zn}$ ions. This hypothesis was supported by studies that demonstrated that NQ acted as an antiangiogenic agent both in vitro and in vivo. ${ }^{84}$

It is notable that $\mathrm{Cu}$ ions enhanced the cytotoxic activity found in NQ. ${ }^{96}$ While $\mathrm{Zn}$ ions are known to enhance cytotoxic activity, the activity is found only in association with compounds containing an iodine moiety on the C-7 position of quinoline rings, such as CQ. ${ }^{96}$ However, the mechanism by which $\mathrm{Zn}$ enhances the cytotoxic activity has not been fully elucidated. ${ }^{96}$ The neurotoxicity of CQ has been reported to be involved with the $\mathrm{Zn}$ transporting activity. ${ }^{86,97} \mathrm{CQ}$ that contains iodine at the $\mathrm{C}-7$ position is capable of acting as a $\mathrm{Zn}$ ionophore, while NQ does not. ${ }^{96}$ Such an observation explains why NQ is less neurotoxic than CQ. Moreover, neurological diseases have not been reported in patients treated with $\mathrm{NQ},{ }^{98}$ suggesting that NQ is a novel compound with less neurotoxicity and should be further developed as an anticancer drug.

Recently, glucoconjugates of $8 \mathrm{HQ}$ derivatives (Figure 9) were developed as anticancer prodrugs in order to improve the selectivity and to avoid chelation of systemic metal ions. ${ }^{99}$ It was reported that glucose avidity, increased glycolysis rate, and overexpression of glucose transporters were found in cancer cells. ${ }^{100}$ The study indicated that glucoconjugates could enhance drug delivery owing to the presence of the glucose moiety in drug molecules. The molecular structures of conjugated glucose can mask the chelating properties of compounds until they reach their target sites. Moreover, the presence of glucose in the drug structure promotes a more selective action by exploiting glucose transporters, which were found to be overexpressed in cancer cells. ${ }^{99}$ Therefore, glucoconjugated drugs are more selective to cancer cells and can cause less systemic side effects. ${ }^{99}$ After glucoconjugates are trapped in target cells, glucose moieties are hydrolyzed by specific $\beta$-glucosidases, which allows the compounds 


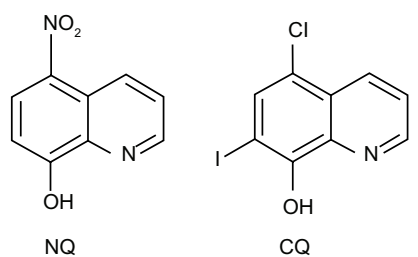

Figure 8 Chemical structures of nitroxoline (NQ) and clioquinol (CQ).

to display chelation and exert antiproliferative effects. ${ }^{101}$ It has been demonstrated that $8 \mathrm{HQ}$-glucoconjugates are novel compounds with potential for further development as selective anticancer treatment. ${ }^{99}$

\section{Antimicrobial activity}

Antimicrobial effects of $8 \mathrm{HQ}$ and its derivatives encompassing antibacterial, ${ }^{102-104}$ antimalarial, ${ }^{105-107}$ antiviral, ${ }^{108}$ antitubercular, ${ }^{109}$ and antidental plaque activities ${ }^{110,111}$ have been previously reported.

\section{Antibacterial activity}

\section{Antitubercular activity}

Nonreplicating Mycobacterium tuberculosis (TB) or latent TB is more tolerant to most antituberculosis drugs than the replicating type of TB and requires a more prolonged treatment. ${ }^{109}$ In fact, more than $2008 \mathrm{HQ}$-like compounds were identified to have an inhibitory effect against replicating TB. ${ }^{112}$ Results showed that $8 \mathrm{HQ}$ itself exerted the most potent activity among other compounds in its class. ${ }^{113} 8 \mathrm{HQ}$ can kill both replicating and nonreplicating TB in vitro, with a more potent effect noted for the nonreplicating type. ${ }^{109}$ Moreover, toxicity toward mammalian cells was not observed within the tested range of concentrations $(0.1-10 \mu \mathrm{M})$, suggesting its safety in humans. ${ }^{109}$ Insight into its mechanism of action was not fully elucidated; however, the bidentate chelating property of $8 \mathrm{HQ}$ was probably not the primary mechanism. This

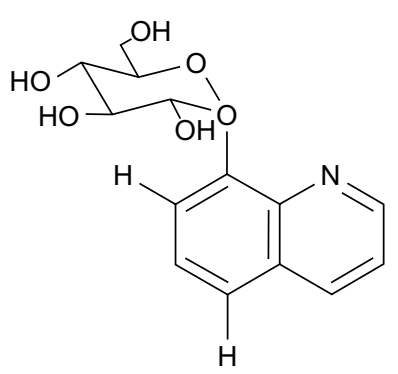

Glu8HQ

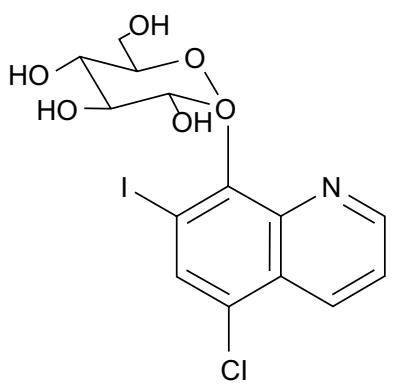

GluCQ
Figure 9 Glucoconjugates of 8-hydroxyquinoline and clioquinol.

Abbreviations: Glu8HQ, glucoconjugate of 8-hydroxyquinoline; GluCQ, glucoconjugate of clioquinol. was supported by the finding that the minimum inhibitory concentration (MIC) value was not changed by the addition of metal ions such as $\mathrm{Fe}, \mathrm{Cu}, \mathrm{Mn}, \mathrm{Zn}$, or Ni. ${ }^{109}$ Therefore, it was suggested that $8 \mathrm{HQ}$ interacts with several molecular targets to evade TB resistance. ${ }^{109}$

Most of the clinically used antituberculosis drugs are known to be more active against replicating TB and are able to kill both types of TB. The more potent actions were exhibited against the nonreplicating type as was observed in $8 \mathrm{HQ}$, which has not been reported in the literature. ${ }^{109}$ Thus, $8 \mathrm{HQ}$ could be a promising compound for the improvement of TB treatment. ${ }^{109}$

The antitubercular activity of CQ-metal complexes were also reported. ${ }^{113}$ In particular, a series of mixed ligand metal complexes using CQ and 1,10-phenanthroline as ligands to coordinate with transition metal ions were synthesized and tested for antitubercular and antifungal activities. ${ }^{113}$ It was found that the $\mathrm{Mn}$ (II) complex was active against TB (MTCC200) with comparable MIC to the standard drug rifampicin with MIC values of $45 \mu \mathrm{g} / \mathrm{mL}$ and $40 \mu \mathrm{g} / \mathrm{mL}$, respectively, ${ }^{113}$ whereas the $\mathrm{Co}$ (II) complex showed more potent activity with MIC 6.4-fold less than that of rifampicin. ${ }^{1{ }^{13}}$ This study showed that free ligands and metal complexes exerted higher antitubercular activity than that of metal salts. ${ }^{113}$

\section{Inhibitory effect on Escherichia coli}

A previous study reported the antimicrobial effects of 8HQ and its derivatives including 2-hydroxyquinoline (2HQ), 4-hydroxyquinoline (4HQ), and 6-hydroxyquinoline (6HQ) as well as 2-methyl-8HQ against human intestinal bacteria (Bifidobacterium longum, Clostridium difficile, Clostridium perfringens, E. coli, Lactobacillus acidophilus, and Lactobacillus casei). ${ }^{103}$ The results from the paper disc agar diffusion method demonstrated that only $8 \mathrm{HQ}$ could exhibit anti-intestinal bacterial activity. Strong inhibition was also observed for $E$. coli and $C$. difficile at a concentration of $0.5 \mathrm{mg} /$ disc and for $C$. perfringens at a concentration of $0.1 \mathrm{mg} /$ disc. The SAR study indicated that different positions of the hydroxyl group but not the methyl group on the quinoline ring gave rise to growth inhibitory activity against intestinal bacteria. Particularly, compounds with an $\mathrm{OH}$ group at the C-8 position displayed effective E. coli, C. difficile, and $C$. perfringens inhibitions. ${ }^{103}$ On the other hand, $2 \mathrm{HQ}$, $4 \mathrm{HQ}$, and 6HQ showed no growth inhibition against all of the tested intestinal bacteria.

\section{Inhibitory effect on Staphylococcus aureus}

Aqueous formulation of 8HQ (0.5\% 8HQ), or commercially available as $\mathrm{AQ}^{+}$, was reported to strongly 
inhibit the growth of $S$. aureus including methicillinresistant $S$. aureus (MRSA), methicillin-susceptible $S$. aureus, and vancomycin-intermediate $S$. aureus and displayed median MIC of $0.25 \%$, which is equal to an active ingredient concentration of $12.5 \mu \mathrm{g} / \mathrm{mL}$ at optimum $\mathrm{pH}$ of 9.2. ${ }^{1}$ Lowering of the $\mathrm{pH}$ value caused a reduction in its efficacy: $\mathrm{pH} 7.5$ yielded 4-fold reduction, and $\mathrm{pH} 5.5$ resulted in 8-fold reduction. ${ }^{1}$ Interestingly, MRSA and vancomycinintermediate $S$. aureus were equally susceptible to $\mathrm{AQ}^{+}$as was observed for methicillin-susceptible $S$. aureus. It was suggested that the susceptibility to $\mathrm{AQ}^{+}$was not influenced by antibiotic resistance determinants of the microbe. ${ }^{1}$ Data from electron microscopy indicated that $\mathrm{AQ}^{+}$actively disrupts bacterial cell walls thereby leading to cell lysis. ${ }^{1}$ A timekilling study showed that $\mathrm{AQ}^{+}$killed $99.9 \%$ of all bacterial cells from tested isolates within 6 hours. The time-killing curve of $\mathrm{AQ}^{+}$was similar to that of gentamicin. Moreover, at higher concentration of $\mathrm{AQ}^{+}$, a more rapid killing effect was observed. ${ }^{1}$ MRSA is carried in the anterior nares, and it should be noted that mupirocin-containing nasal ointment is currently being used to prevent transmission; however, antibiotic resistance had been reported to increase. ${ }^{113}$ Owing to the lipophilicity of $8 \mathrm{HQ}$ and its potency against various $S$. aureus strains as well as its rapid killing nature, it has been suggested that this compound could be used as topical hand cleansing agent to prevent MRSA transmission. ${ }^{1}$

The efficacy of $8 \mathrm{HQ}$ in inhibiting $S$. aureus is dependent on its chelating ability and is enhanced in the presence of $\mathrm{Cu}$. In addition, 8HQ derivatives were found to inhibit $S$. aureus strains. ${ }^{102}$ Quantitative structure-activity relationships (QSAR) study performed on 24 substituted 8HQ derivatives showed that ten three-dimensional descriptors such as molecular refraction (MR), partition coefficient $(\log \mathrm{P})$, total energy (E), standard Gibbs free energy $(G)$, lowest unoccupied molecular orbital (LUMO), highest occupied molecular orbital (HOMO), total molecular energy (TotE), Wien index (WInd), Balaban index (BInd), and octanol-water ClogP were significant for the development of highly predictive $\left(R^{2}=0.988\right)$ model. ${ }^{102}$ Moreover, potent activity was found in ester derivatives rather than styryl derivatives. ${ }^{102}$

\section{Antidental plaque activity}

Antidental plaque activity of $8 \mathrm{HQ}$ derivatives has been reported. ${ }^{110,111}$ Dental plaque is a combination of oral microorganisms colonized on oral surfaces in which a microbial consortium or oral biofilm is formed. ${ }^{115}$ Mutans streptococci and Porphyromonas gingivalis are the most important among such oral microorganisms since they are pathogens of dental caries and periodontal diseases, respectively. ${ }^{115}$ At equilibrium, oral biofilms are beneficial for the prevention of exogenous and potentially pathogenic species colonization. However, unfavorable disruption of dynamic balance between host and microbial community at local sites eventually leads to an overgrowth of virulent or pathogenic species causing diseases. ${ }^{116}$ Mutans streptococci comprises two species, Streptococcus mutans and S. sobrinus, in which S. mutans is highly prevalent in dental plaque and is considered as an etiological pathogen for dental caries. ${ }^{117}$ An in vitro study of antidental plaque activity of three $8 \mathrm{HQ}$ derivatives, namely $8 \mathrm{HQ}$ sulfate, 5-chloro-7-iodo-8HQ (or CQ), and 5,7-dichloro-8HQ, against S. mutans, Streptococcus sanguis, Actinomyces viscosus, and Actinomyces naeslundii was reported. The result showed that all 8HQ derivatives differentially inhibited each of the tested organisms. ${ }^{111}$ These compounds were prepared in percentage concentrations in polyethylene glycol owing to their sparingly water-soluble nature. ${ }^{11} \mathrm{CQ}$ and 5,7-dichloro-8HQ exerted a bactericidal effect at $0.05 \%$ concentration on $S$. mutans (cariogenic) and A. viscosus (periodontogenic), whereas $8 \mathrm{HQ}$ sulfate showed a bacteriostatic effect against both pathogens at a higher $(0.3 \%)$ concentration. ${ }^{111}$ It was demonstrated that halogenated $8 \mathrm{HQs}$ were more potent dental plaque inhibitors. ${ }^{10,111}$ The low water solubility is a limitation in using these bioactive compounds via an aqueous vehicle such as mouth rinse. ${ }^{111}$ However, such compounds could be used via a polyethylene glycol vehicle as an ointment or additive ingredient in dentifrice to control dental diseases. ${ }^{111}$

It is widely known that the antibacterial activity of $8 \mathrm{HQ}$ is closely related with its chelating ability, therefore, Fe or $\mathrm{Cu}$ chelation is required for the activity. ${ }^{110}$ Previous SAR studies indicated that substitution near the nitrogen atom or the phenolic group could alter the chelating ability, which led to a reduction of the antimicrobial activity. ${ }^{118,119}$ This study demonstrated that the hydrophobic $\log \mathrm{P}$ parameter alone is not adequate for accurate computational prediction. Thus, electronic parameters such as $\mathrm{pKa}$ and steric parameters including MW and molecular refractivity are required for antidental plaque prediction. ${ }^{110}$ The QSAR study showed that two main factors are involved in antidental plaque activity of 8HQ against $S$. mutans. ${ }^{110}$ The results revealed that compounds with increased lipophilicity and electron-withdrawing substituents at the 5-position led to improvements in the activity, whereas bulky substituent groups afforded a decrease in the activity. ${ }^{110}$ According to these findings, the most potent $S$. mutans inhibitor should contain small C-5 substituents with lipophilicity and electron-withdrawing properties. ${ }^{110}$ 
Notably, CQ contains a 5-chloro group with lipophilicity and an electron-withdrawing nature, making this compound a good $S$. mutans inhibitor. ${ }^{110}$

\section{Antimicrobial activity of metal complexes and novel compounds Metal-8HQ complexes}

The antimicrobial activity of divalent metal-8HQ complexes and their mechanisms of action have been proposed. ${ }^{120}$ It was assumed that 8HQ uses its high lipophilicity to penetrate bacterial cell membranes in order to reach its target site of action, which could possibly be a metal-binding site of bacterial enzymes. The metal-8HQ complex will dissociate into a 1:1 ratio of $8 \mathrm{HQ}-$ metal charged complex and $8 \mathrm{HQ}$ free ligand. ${ }^{120}$ The charged $8 \mathrm{HQ}$ metal complex can bind and block the metal-binding sites on bacterial enzymes, which gives rise to the antimicrobial effect. ${ }^{119}$ Therefore, the lipophilicity, as indicated by the $\log \mathrm{P}$, is considered to be an important factor for antimicrobial activity of the investigated compounds. ${ }^{120}$ In addition, the dissociated free ligand of $8 \mathrm{HQ}$ possesses high chelating ability that could bind metallic prosthetic groups of microbial enzymes thereby leading to the inhibition of enzymatic activity. ${ }^{5,120}$

Recently, 8HQ-uracil metal complexes bearing antimicrobial activity (Figure 7) have been reported. ${ }^{121}$ The complexes exhibited growth inhibition against many strains of Gram-positive and Gram-negative bacteria including resistant pathogens, such as $S$. aureus, Enterococcus faecalis, and Candida albicans. ${ }^{121}$

Previously, 4-benzenesulfonamide (HQMABS), shown in Figure 10, is a hybrid of 8HQ and sulfanilamide and was reported to be a ligand for metal complexes. ${ }^{5}$ This study showed that HQMABS exhibited more potent antimicrobial activity with higher sensitivity against Gram-positive bacteria as compared to their individual parent compounds (ie, 8HQ and sulfanilamide). ${ }^{5}$ This demonstrates that there is a synergistic effect of $8 \mathrm{HQ}$ and sulfanilamide that facilitates the penetration of HQMABS into the site of action in bacterial cells. ${ }^{5}$ Therefore, HQMABS exhibited antimicrobial effects through a similar mechanism to that of $8 \mathrm{HQ}$, as a membrane active agent via metal ion chelation. ${ }^{122}$ On the other hand, all metal complexes of HQMABS displayed weak to moderate activity as compared to their respective free ligand, HQMABS. Moreover, the antimicrobial activity of these compounds is dependent on the nature of the ligands, concentration and lipophilicity of the compound, nature of metal ions, geometry of the complex, and coordinate sites. ${ }^{5}$

\section{HQ-based quaternary cationic surfactant}

Quaternary cationic surfactants (Figure 11) were synthesized from the reaction of 8HQ and long chain alkyl halides. ${ }^{104}$ The study showed that cationic amphiphilic structures of quaternary salts allowed the compounds to interact with the bacterial lipid bilayer membrane. ${ }^{122}$ The effect may alter the membrane itself or cause toxicity to the membrane thereby leading to bacterial cell death. ${ }^{123}$ The activity of these 8-hydroxyquinolium derivatives is dependent on both the polar heads (ie, size and electronic charge distribution) and the hydrocarbon chain length. ${ }^{104}$ It was found that the activity increased from $\mathrm{C}-12$ to $\mathrm{C}-14$ carbon atoms and decreased in the case of $\mathrm{C}-16 .{ }^{104}$ This suggested that cationic and long chain hydrocarbons of an appropriate length facilitate bacterial killing via membrane attack.

\section{Antiviral activity}

It is well recognized that nucleic acid binding ability is important for RNA-dependent-DNA polymerase inhibition, which is essential for antiviral activity. ${ }^{124}$ Among the groups of tested metal-binding compounds, 8HQ exhibited high antiviral activity with approximately 50-fold higher activity. ${ }^{124}$ Moreover, the binding activity of the $\mathrm{Cu}$ complexes of 8HQ and its derivatives were significantly higher than their respective free ligand forms. ${ }^{124}$ Interestingly, this activity was enhanced markedly when an equimolar concentration of $\mathrm{Cu}$ was added. ${ }^{124}$ According to Albert et al, ${ }^{119}$ the ratio of metal complex and their free ligand was shown to affect their antibacterial and antifungal activities; particularly only the 1:1 ratio provided the activity. It was found that increasing the amount of ligands resulted in the formation of more inactive complexes, thereby resulting in decreased activity - which is known as concentration quenching. This phenomenon was observed when high concentrations of drugs gave rise to lower inhibition of DNA synthesis in comparison to using a low drug concentration. ${ }^{124}$ Despite binding to viral nucleic acid, another possible mechanism of antiviral activity is its binding to $\mathrm{Zn}$ in enzymes, thereby leading to the inactivation of viral enzymes. ${ }^{125,126}$ However, the stability of the $\mathrm{Cu}$ complex is much greater than that of the $\mathrm{Zn}$ complex. ${ }^{127}$ This was supported by the study demonstrating that the $8 \mathrm{HQ}-\mathrm{Cu}$ complex inhibited RNA-dependent-DNA polymerase as well as inactivating Rous sarcoma virus and herpes simplex virus with comparable activity as to that of 8HQ free ligand. ${ }^{112}$ Therefore, antiviral activity as exerted by ligand binding to Zn metalloenzymes may not be possible. ${ }^{112}$

Macrocyclic polyamines such as AMD3100 (Figure 12) has reached Phase II of clinical trials and is considered to 


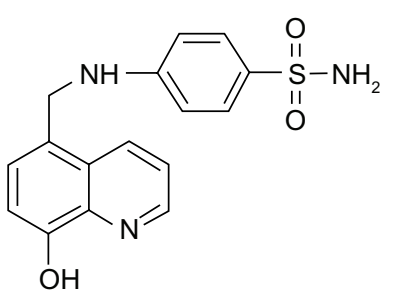

HQMABS

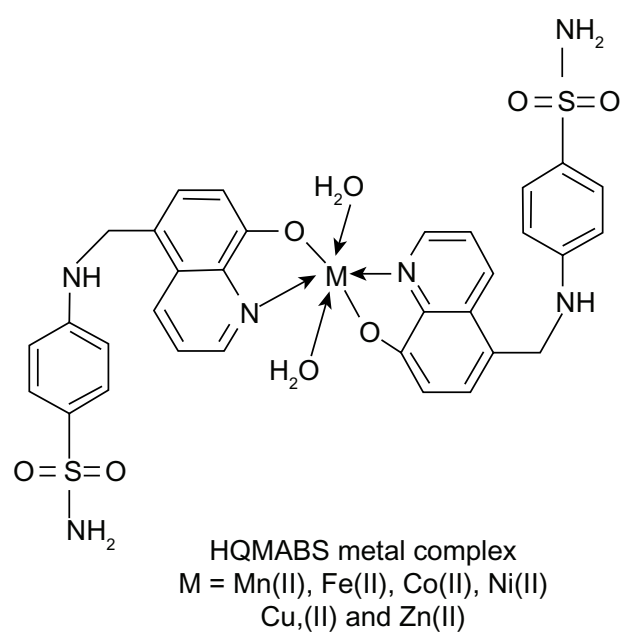

Figure 10 Chemical structures of HQMABS and metal complexes.

Abbreviation: HQMABS, 4-benzenesulfonamide.

be a prototype for an antihuman immunodeficiency virus compound. ${ }^{108}$ AMD3100 is known to block host cell entry via blocking cell surface G-protein-coupled receptors, such as CCR5 and CXCR4, which are chemokine receptors. ${ }^{128-130}$ Hydroxyquinoline-polyamine conjugates (Figure 13) were synthesized using hydroxyquinoline conjugation with polyamine backbones or polyazamacrocycles in order to mimic chemokine receptor antagonists. ${ }^{108}$ The results showed that the conjugated compounds elicited antihuman immunodeficiency virus activity against two viral strains, Human immunodeficiency virus (HIV), 1 LAV and HIV-1 $\mathrm{BaL}$, whereas $\mathrm{CQ}$ and polyazamacrocycle were shown to be inactive. ${ }^{108}$ Interestingly, AMD3100 (the reference compound) is only active against HIV-1 LAV thereby suggesting that the quinoline moiety is necessary for conjugated polyamine compounds as anti-HIV agents against both viral strains. ${ }^{108}$

\section{Antiparasitic activity}

\section{Antimalarial activity}

Malaria is considered to be a life-threatening infectious disease worldwide. ${ }^{131}$ Quinoline-containing compounds have been used for malarial treatment, such as quinine. ${ }^{132}$

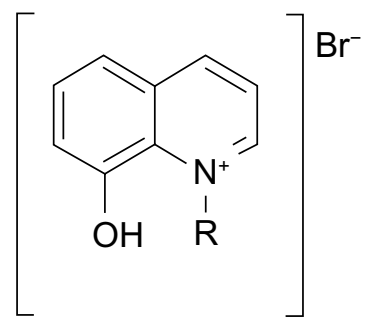

$\mathrm{R}=\mathrm{n}$-dodecyl, n-tetradecyl and n-hexadecyl

Figure I I Quaternary ammonium salts of 8-hydroxyquinoline.
Unfortunately, drug-resistance has been continuously reported ${ }^{107}$, thus, the search for novel quinolone-based compounds is a demanding issue. ${ }^{133}$ Studies have shown that high sensitivity of human malaria to such compounds is mainly due to high lipid-water $\log \mathrm{P}$ and metal-binding constants. ${ }^{134-139}$ It was noted that the inhibition of Plasmodium falciparum multiplication and the chelating ability of the compounds were directly correlated. ${ }^{106}$ Chelators are known to interact with parasitic enzymes in different ways, such as by interacting with sulfhydryl groups, with amino groups, and with certain metal ions of enzymes. ${ }^{137}$ 8HQ as a potent chelator with high lipophilicity, and is known to possess an antimalarial effect against the intracellular stage of malaria in red blood cells by inhibiting a variety of metalloprotein oxidase enzymes, thereby resulting in the inhibition of glycolysis and parasitic growth. ${ }^{135}$ In vivo toxicity of $8 \mathrm{HQ}$ derivatives as diabetogenic agents (Figure 14) has previously been reported. However, a small group of substituents at the C-5 and C-7 positions on the quinoline ring can markedly lower the toxicity in higher animals. ${ }^{106}$

Substitution with a chlorine group at the C-5 or at both the C-5 and C-7 positions of 8HQ (Figure 14A and $\mathrm{B}$, respectively) was shown to increase the lipid solubility and chelating ability of the compounds. These increases are expected to be an effect of the phenolic group that leads to improvement in metal chelation. ${ }^{106}$ Surprisingly, in this case, an improvement of the antimalarial activity was not observed. ${ }^{106}$ Unlikely to be found in bacterial systems, the addition of an extra aromatic ring at the C-5 and C-6 positions (Figure 14C and 14D, respectively) was shown to not only increase its lipophilicity but also led to a decrease in its antimalarial activity. This could be attributed to the bulky 


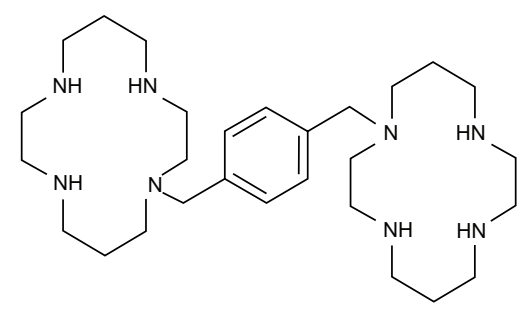

Figure 12 Structure of AMD3100.

structures of the aromatic ring, that may cause steric effects and thereby hinder the compound from interacting with macromolecules on plasmodial enzymes or receptor sites. ${ }^{106}$ It was suggested that the substitution of $\mathrm{C}-5$ or $\mathrm{C}-7$ positions with electron-withdrawing groups or aromatic rings could improve the lipophilicity of the compounds and is likewise beneficial for drug delivery to target an intracellular site of action. Thus, improved chelating ability and reduced in vivo toxicity were observed, but antimalarial activity showed no improvement. This indicated that the antimalarial effect as afforded by these compounds may be contributed to other factors. ${ }^{106}$

\section{Linkages of antiparasitic and anticancer activities} Metabolic pathways in intracellular parasites (ie, $T$. gondii and $P$. falciparum) and in cancer cells are more sensitive to
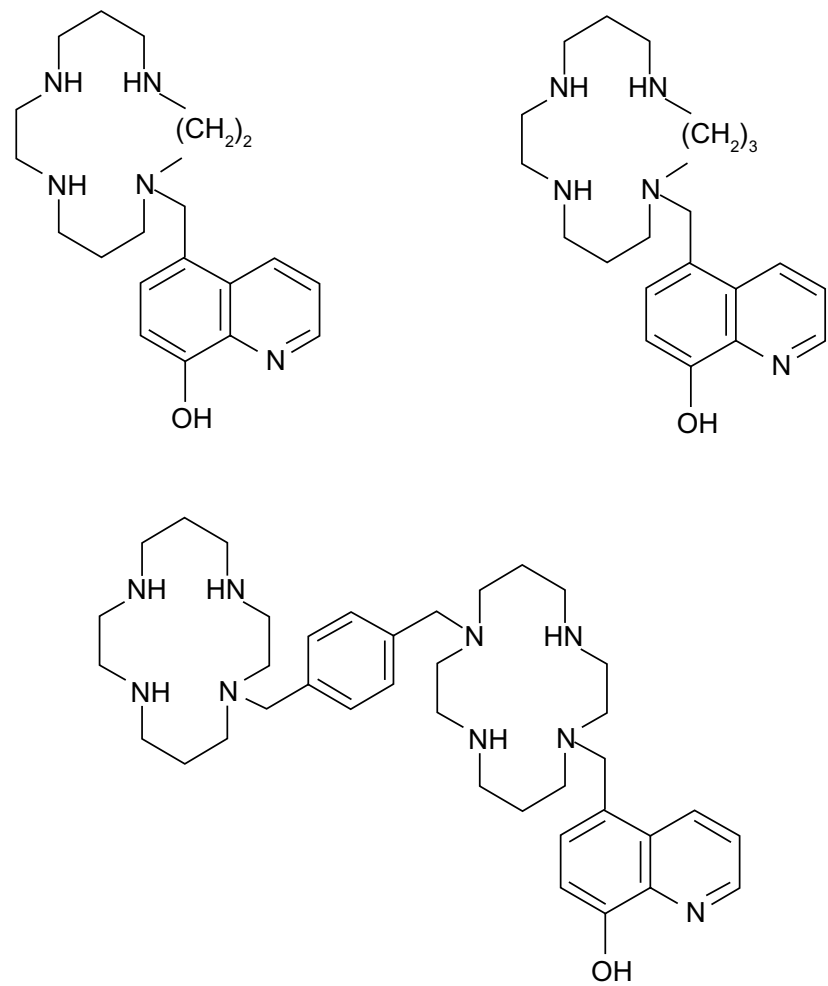

Figure 13 Chemical structures of hydroxyquinoline-polyamine conjugates using hydroxyquinoline conjugation with polyamine backbone or polyazamacrocycles. oxidative stress than normal cells and are dependent upon glycolysis in order to produce energy. In addition, some anticancer drugs were found to have antimalarial activity. ${ }^{138-140}$ Results from computational screening of quinoline-based antitumor compounds showed that nitrogen substitution at the $\mathrm{C}-5$ position of the quinoline ring is required for antiprotozoal activity. Apparently, 5-nitroso-8HQ (NSC3852) (Figure 15) exerted the most potent predicted activity and is therefore relevant to the experimentally observed activity against $T$. gondii, with a half maximal effective concentration of $78.6 \mathrm{nM}$. But, its activity against $P$. falciparum was found to be eight times less active than that for T. gondii. ${ }^{105}$ So far, NSC3852 was reported to exert anticancer activity as elicited through the production of superoxide anion and nitric oxide (NO) against breast cancer cells. ${ }^{141}$ In contrast, antiprotozoal activity of NSC3852 was attributed to different mechanisms. ${ }^{105}$ Particularly, it was hypothesized that NSC3852 increased the intracellular oxidative stress via indirect mechanisms. This involves arylation of protein sulfhydryls and the depletion of intracellular glutathione, ${ }^{142}$ which resulted in the metabolism of NSC3852 to non-redox cycling naphthoquinone and NO release from the nitroso group of the compound. ${ }^{105}$

Interestingly, antiparasitic and anticancer activities of 8HQ derivatives are potentiated upon complexation with metal ions such as $\mathrm{Cu}$ and $\mathrm{Zn} .{ }^{84} \mathrm{~A}$ series of antimony8HQ complexes were synthesized and found to exhibit more potent antitrypanosomal and cytotoxic activities when compared to $\mathrm{Sb}$ salt $\left(\mathrm{SbCl}_{3}\right)$ and their free ligands, which are 8HQ, 5-chloro-8HQ, and 5-chloro-7-iodo-8HQ (or CQ). ${ }^{143}$

\section{Antioxidant activity}

Oxidative damage is frequently found in many diseases such as aging, atherosclerosis, cancer, diabetes, ${ }^{144}$ and neurodegenerative diseases. ${ }^{7}$ Free radicals are continuously produced in cells through a wide range of biological processes. ${ }^{144}$ For example, the changing oxidation stage of $\mathrm{Cu}$, which is a cofactor of SOD, results in the generation of ROS. ${ }^{145}$ Therefore, antioxidant defenses, such as those afforded by tocopherol, ascorbic acid, SOD enzyme, and catalases, are necessary in the maintenance of homeostasis. ${ }^{146}$ Many phenolic compounds, derived from either natural sources or synthetic methods, have been reported as potent antioxidants. ${ }^{147-149}$ An effective antioxidant activity of phenolic compounds is dependent on the stability of the phenoxyl radical formed in the reaction ${ }^{150}$ as well as the position of a substituent which affects the phenoxyl radical. ${ }^{151}$ 
$8 \mathrm{HQ}$ derivatives have been reported as potent antioxidants, ${ }^{32,37,152,153}$ which arises from their chelating ability. It is widely known that mixed ligand metal complexes can commonly occur in biological fluids from various bioactive ligands with metal ions. ${ }^{154}$ Interest in the area of metal complexation has steadily increased. SOD is one of the most useful antioxidant enzymes, known to convert superoxide into $\mathrm{H}_{2} \mathrm{O}_{2}$ and oxygen. ${ }^{155}$ However, this enzyme has certain limitations such as short shelf-life, low lipid solubility, low penetration into the cell, ${ }^{155}$ and high MW. ${ }^{156}$ The SOD structure has a central metal atom surrounded by the protein structure, thus, accordingly, great focus has been reported on the synthesis of small-sized lipophilic metal complexes in efforts to mimic the SOD activity. ${ }^{63,157,158}$

A series of mixed ligand metal complexes using $8 \mathrm{HQ}$, 5-iodouracil, and 5-nitrouracil as ligands were synthesized and studied for their antioxidant activity using SOD assay. ${ }^{63}$ The results showed that amongst the different tested metal complexes, the 5-iodouracil-Mn-8HQ complex was shown to exert the highest activity, with a $\mathrm{IC}_{50}$ of about 3-fold less than that of the free ligand $8 \mathrm{HQ} .{ }^{63}$ This indicated that the coordination of metal ion into the free ligand can lead to enhancement of SOD activity. ${ }^{63}$ However, complexation of different types of metal ions with the same combination of ligands resulted in different bioactivities. ${ }^{65}$

\section{Anti-inflammatory activity}

Nitric oxide is a short-lived free radical product generated by the conversion of L-arginine to L-citrulline, which is facilitated by nitric oxide synthase (NOS). ${ }^{159}$ There are three isoforms of NOS comprised of endothelial NOS, inducible NOS (iNOS), and neural NOS. ${ }^{160}$ Small amounts of NO<smiles>Oc1ccc(Cl)c2cccnc12</smiles>

A

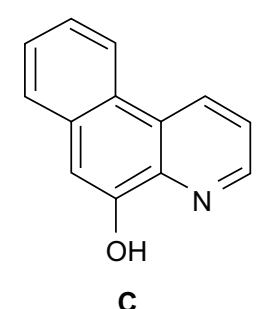

C<smiles>Oc1c(Cl)cc(Cl)c2cccnc12</smiles>

B<smiles>Oc1cc2cccnc2c2cccnc12</smiles>

D

Figure 14 Substituted 8-hydroxyquinoline derivatives.

produced by endothelial NOS and neural NOS were shown to play important roles in the maintenance of homeostasis. In contrast, large amounts of NO from iNOS is generated in pathological conditions and inflammation. ${ }^{161} \mathrm{NO}$ production is regulated by the expression of the $i N O S$ gene, ${ }^{162}$ which is mainly modulated at the transcriptional level via the binding of transcription factors to sites such as NF- $\kappa$ B sites, activator protein-1, interferon regulatory factor 1 , and CCAAT/ enhancer-binding protein $\beta(\mathrm{C} / \mathrm{EBP} \beta) .{ }^{163}$ The $\mathrm{NF}-\kappa \mathrm{B}$ site is essential for lipopolysaccharide-mediated NO production in response to inflammation. ${ }^{164}$ Macrophage-derived NO acts as a host-defense mechanism against microbes and tumors, as well as a regulator of proinflammatory genes in vivo. ${ }^{159} \mathrm{It}$ has been found that $8 \mathrm{HQ}$ inhibits lipopolysaccharide-induced NO production. Particularly, it suppresses iNOS mRNA expression and $i N O S$ promoter activity by inhibition of NF- $\kappa \mathrm{B}$ activation and $\mathrm{C} / \mathrm{EBP} \beta$ DNA-binding activity. ${ }^{160}$ The study demonstrated that $8 \mathrm{HQ}$ possesses anti-inflammatory activity and could be further developed for the treatment of inflammatory diseases. ${ }^{160}$

\section{$\mathrm{Pb}$ transportation across erythrocyte membranes}

Long-term exposure to $\mathrm{Pb}$ from the environment causes lead poisoning. $\mathrm{Pb}$ accumulation is found in bone tissue ${ }^{165}$ and is also distributed to other organs. ${ }^{166}$ Moreover, $\mathrm{Pb}$ accumulation in bone tissue is correlated with an increased risk of cardiovascular mortality, ${ }^{167}$ cognitive changes, and neurodegenerative diseases. ${ }^{168,169}$ The majority of $\mathrm{Pb}$ in whole blood is not found in the plasma but is sequestered in erythrocytes, which take up $\mathrm{Pb}$ via anion exchangers. ${ }^{83}$ The accumulation of $\mathrm{Pb}$ in erythrocytes affects erythrocyte enzymes, especially $\Delta$-ALA dehydratase ${ }^{170}$ and 5-nucleotidase. ${ }^{171}$ Such accumulation also accelerates the vascular clearance of red blood cells ${ }^{172}$ and thrombin generation, ${ }^{173}$ which may lead to an increased risk of developing cardiovascular disease. ${ }^{174}$ Most of the chelators that are employed for chelation therapy are not capable of passing across the erythrocyte membrane. Thus, the effective

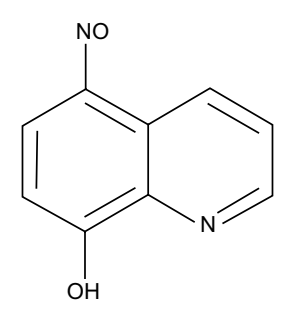

Figure 15 Structure of NSC3852.

Abbreviation: NSC3852, 5-nitroso-8-hydroxyquinoline. 
reduction of the total body $\mathrm{Pb}$ level is not achieved and gives only a short period of therapeutic benefit. ${ }^{83,175}$ Therefore, a combination of $\mathrm{Pb}$ ionophore and $\mathrm{Pb}$ chelating agent was recommended as a new strategy for lowering total body $\mathrm{Pb}$ accumulation. ${ }^{176}$

$\Delta$-ALA dehydratase is well recognized as a $\mathrm{Zn}$ containing erythrocyte enzyme. ${ }^{83} \mathrm{~Pb}$ is believed to displace $\mathrm{Zn}$ from the enzyme, thereby leading to enzyme inactivation. However, the addition of $\mathrm{Zn}$ has been reported to restore $\Delta$-ALA dehydratase activity in vivo. ${ }^{177,178}$ Since $\mathrm{Pb}$ ions enter erythrocytes through anion channels, if they were not trapped in extracellular areas they could reenter cells. ${ }^{83}$ Thus, the increase of intracellular $\mathrm{Zn}$ may reverse $\mathrm{Pb}$ binding and facilitate the release of $\mathrm{Pb}$ from the enzyme. This potentiates intracellular $\mathrm{Pb}$ ions to exit from erythrocytes into the extracellular space, where they are effectively eliminated by $\mathrm{Pb}$ chelators. ${ }^{83}$

CQ is a hydrophobic halogenated $8 \mathrm{HQ}$ derivative known to act as a $\mathrm{Zn}$ ionophore. It is capable of transporting $\mathrm{Zn}$ across the cellular membrane. ${ }^{80}$ An in vitro study demonstrated that $\mathrm{CQ}$ acting as a $\mathrm{Zn}$ ionophore could facilitate $\mathrm{Pb}$ escape from erythrocytes into the extracellular space. An increased intracellular $\mathrm{Zn}$ level thereby allows more effective chelation. ${ }^{83}$ This suggested that $8 \mathrm{HQ}$ derivatives and other classes of $\mathrm{Zn}$ ionophore could be further developed as a combined agent, acting as $\mathrm{Pb}$ chelators by lowering the total body $\mathrm{Pb}$ accumulation. ${ }^{83}$

\section{Building block for artificial carbohydrate receptors}

Artificial carbohydrate receptors exploiting carbohydratebased molecular recognition processes via noncovalent interactions of sugar binding ${ }^{179-181}$ have been developed (Figure 16) for diagnostic and therapeutic purposes. ${ }^{182}$ Binding preference in carbohydrate recognition is an important factor for effective systemic outcome. ${ }^{183} \mathrm{An}$ in vitro study demonstrated that 8HQ-based receptors elicited higher affinity to $\beta$-galactoside as compared to that of quinoline-based receptors. ${ }^{183}$ Moreover, the addition of more $8 \mathrm{HQ}$ moieties into the receptor can potentiate higher affinity. ${ }^{183}$ It was suggested that the quinoline hydroxyl group plays an important role in complex formation and molecular recognition of carbohydrates. Therefore, 8HQ-based compounds could potentially be used as a building block for artificial carbohydrate receptors. ${ }^{183}$

\section{Potential antidiabetic activity}

Insulin/insulin-like growth factor-1 signaling pathway (IIS) is an evolutionarily conserved pathway, which regulates

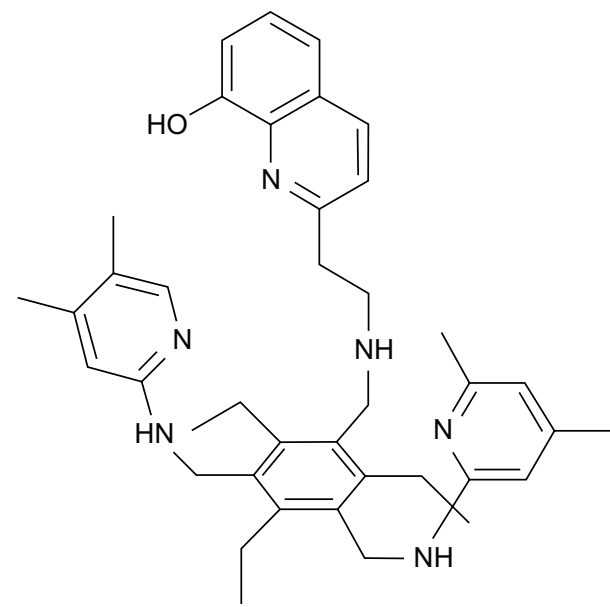

Figure 16 8-Hydroxyquinoline is used as a building block for artificial carbohydrate receptors.

lifespan and longevity in various species from nonvertebrates to humans. ${ }^{184}$ In nonhuman organisms, decreased IIS has been found to be associated with extended lifespan and protection against oxidative stress damage. ${ }^{185,186}$ In addition, experiments on mouse models also demonstrated a significant role of down-regulated IIS in the maintenance of metabolic homeostasis and oxidative defense. ${ }^{184}$ In humans, individuals with decreased IIS as found in those with Laron syndrome were shown to exhibit a lower rate in the development of diseases of civilization including acne, cancer, and diabetes mellitus (DM). ${ }^{184}$

Forkhead box proteins (FOXO) are crucial regulators against oxidative stress conditions. Activation of FOXO in the

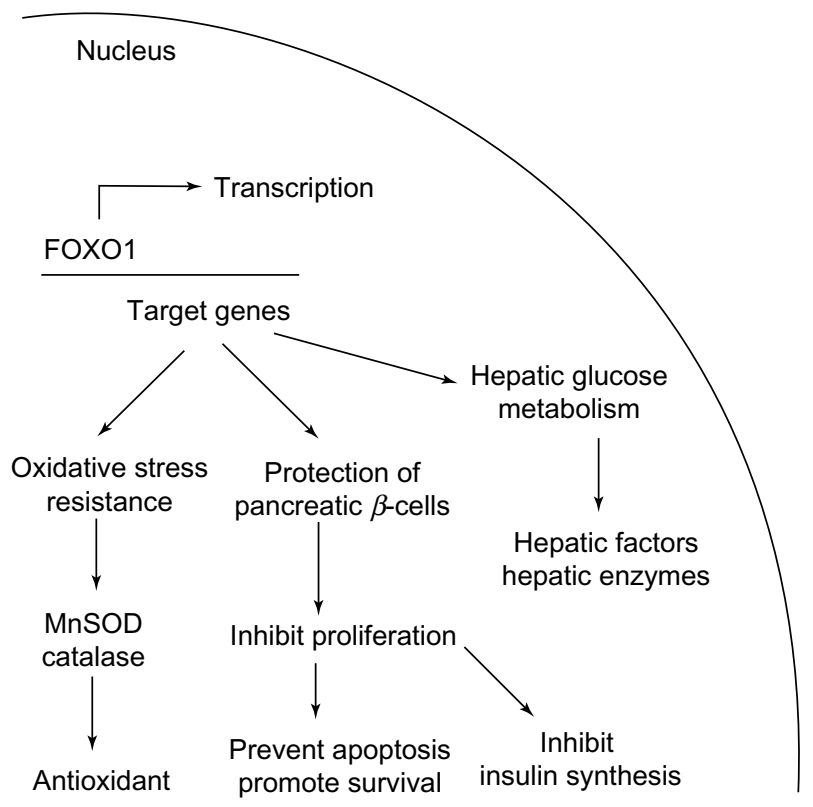

Figure 17 FOXOI functions are related to glucose homeostasis and providing protection against oxidative stress.

Abbreviations: FOXOI, forkhead box protein OI; SOD, superoxide dismutase. 


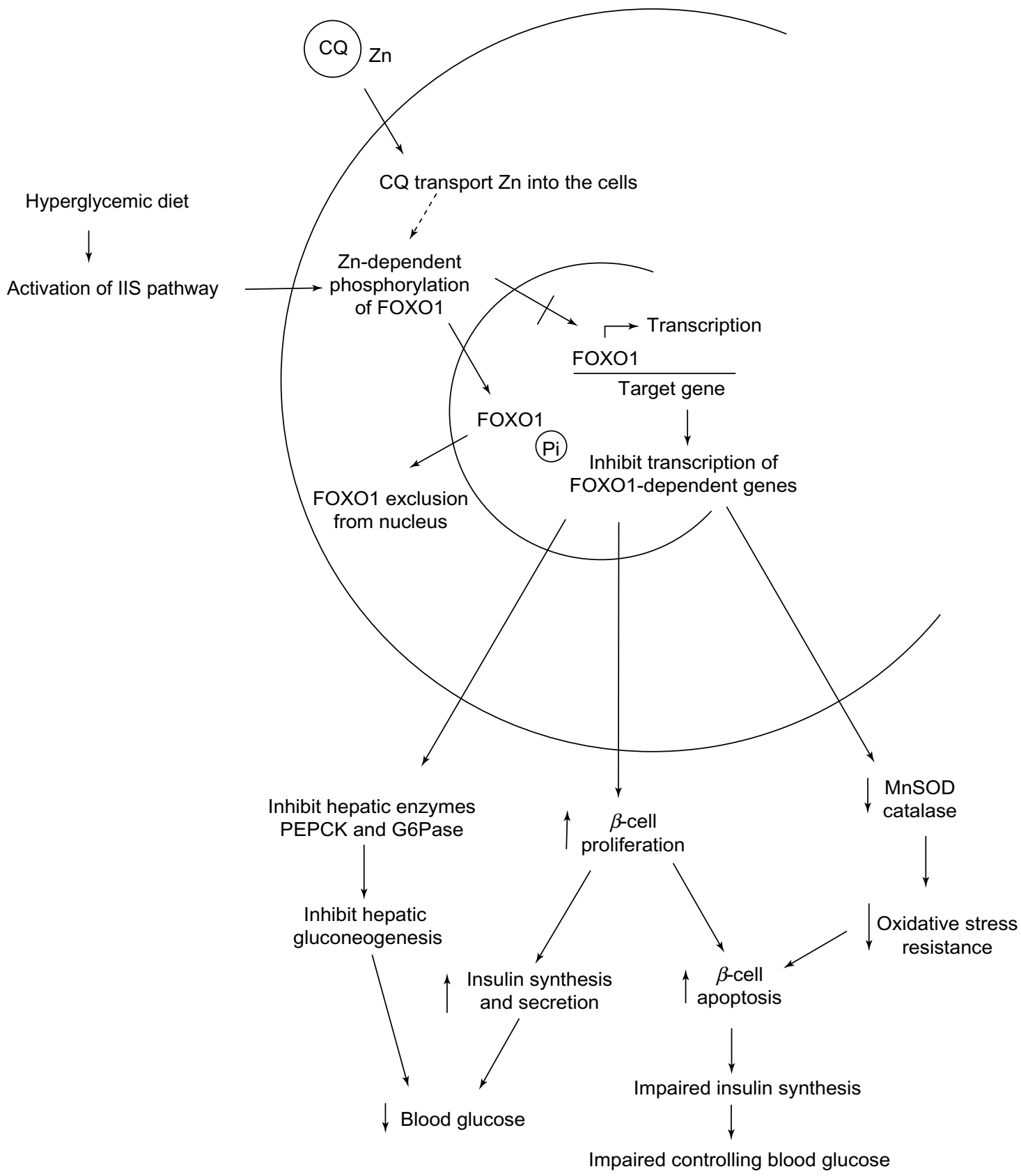

Figure 18 The role of $\mathrm{CQ}$ as $\mathrm{Zn}$ ionophore in controlling blood glucose level via inhibition of FOXOI.

Abbreviations: IIS, Insulin/insulin-like growth factor-I signaling pathway; CQ, clioquinol; FOXOI, forkhead box protein OI; G6Pase, glucose-6-phosphatase; SOD, superoxide dismutase; PEPCK, phosphoenolpyruvate carboxykinase; Pi, phosphorylation.

nucleus results in an expression of many downstream effectors including antioxidant enzyme genes such as superoxide dismutase (MnSOD) and catalase. At the promoter level, FOXO1 induces the expression of the Hmoxl gene (heme oxygenase-1) thereby leading to the reduction of mitochondrial respiration and ROS formation. ${ }^{185}$ Moreover, in pancreatic $\beta$-cell, FOXO1 functions to inhibit $\beta$-cell proliferation and prevent $\beta$-cell apoptosis ${ }^{187}$ as shown in Figure 17. Therefore, the level of nuclear FOXO is important for oxidative stress resistance and cytoprotection of cells. ${ }^{187,188}$
Overstimulated IIS is closely associated with the pathogenesis of DM. Overconsumption of hyperglycemic diet can cause high blood glucose levels, which induces glucose/FOXO1-mediated $\beta$-cell proliferation in order to produce insulin for controlling blood glucose. ${ }^{188}$ This long-term phenomenon generates insulin resistance and hyperinsulinemia, which are the hallmarks of DM type $2 .{ }^{188}$ IIS is found to regulate nuclear distribution of FOXO proteins. ${ }^{185}$ The induction of IIS, caused by hyperglycemic diet, induces $\mathrm{Zn}$-dependent phosphorylation of nuclear 
<smiles>Oc1cccc2cccnc12</smiles>

$8 \mathrm{HQ}$<smiles>Cc1ccc2cccc(O)c2n1</smiles>

8-Hydroxyquinaldine<smiles>O=C(O)c1cc(O)c2cccc(O)c2n1</smiles>

Xanthurinic acid<smiles>O=S(=O)(O)c1ccc(O)c2ncccc12</smiles>

8-Hydroxy-5-sulfonic acid

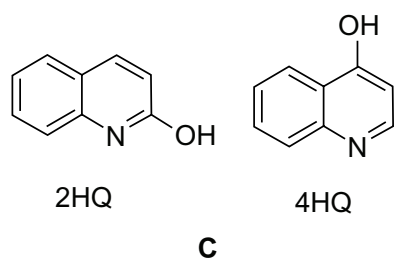

B<smiles>O=C(Cl)c1c(I)cc(Cl)c2cccnc12</smiles>

D

Figure $198 \mathrm{HQ}$ derivatives with different substitutions.

Abbreviations: $\mathrm{CQ}$, clioquinol; $\mathrm{HQ}$, hydroxyquinoline.

FOXO1, ${ }^{189}$ that subsequently triggers their exclusion from the nucleus. ${ }^{185}$

Reduction of nuclear FOXO1 levels as a result of phosphorylation leads to three events. First, an impairment of oxidative stress resistance of $\beta$-cells as caused by downregulation of MnSOD and catalase gene expressions. ${ }^{184}$ Second, an increased proliferation and apoptosis of $\beta$-cells. Third, the inhibition of FOXO1 serves as key regulators for the inhibition of hepatic gluconeogenesis. Therefore, FOXO1 inhibition suppresses hepatic enzymes necessary for glucose production, such as phosphoenolpyruvate carboxykinase and glucose-6-phosphatase, at the transcriptional level. ${ }^{189}$ Obviously the first two events promote $\beta$-cell apoptosis thereby leading to impaired insulin synthesis and altered blood glucose level, while the last event facilitates the lowering of blood glucose as shown in Figure 18.

$8 \mathrm{HQ}$ has been reported as a diabetogenic agent owing to its ability to harm $\beta$-cells. ${ }^{190}$ As a $\mathrm{Zn}$ ionophore, 8HQ carries $\mathrm{Zn}$ into cells in the form of lipophilic, uncharged complexes and releases $\mathrm{Zn}$ inside the cells to promote $\mathrm{Zn}$-dependent FOXO1 phosphorylation thereby leading to oxidative damage and apoptosis of $\beta$-cell. ${ }^{190}$ In addition, acidic proton $\left(\mathrm{H}^{+}\right)$released from the $-\mathrm{OH}$ group of $8 \mathrm{HQ}$ causes damage to $\beta$-cells. ${ }^{190}$

The SAR study of $8 \mathrm{HQ}$ and its derivatives indicated that their binding affinity to $\mathrm{Zn}^{2+}$, charge of complex, and acidity are determinant factors for diabetogenicity of the investigated compounds. ${ }^{190}$ As mentioned, FOXO1 phosphorylation is $\mathrm{Zn}$-dependent, therefore, compounds that possess affinity to bind and form uncharged complexes with $\mathrm{Zn}$ are also capable of penetrating into cells thereby leading to the induction of FOXO1 phosphorylation and the triggering of its exclusion from the nucleus. ${ }^{190}$ Reduced nuclear FOXO1 levels ultimately lead to $\beta$-cell destruction and apoptosis. ${ }^{190}$

A series of $8 \mathrm{HQ}$ and derivatives containing $\mathrm{OH}$ groups at different positions on the quinoline ring (ie, 2HQ and $4 \mathrm{HQ}$ ) as well as ionizable functional groups (ie, $\mathrm{CO}_{2} \mathrm{H}$ and

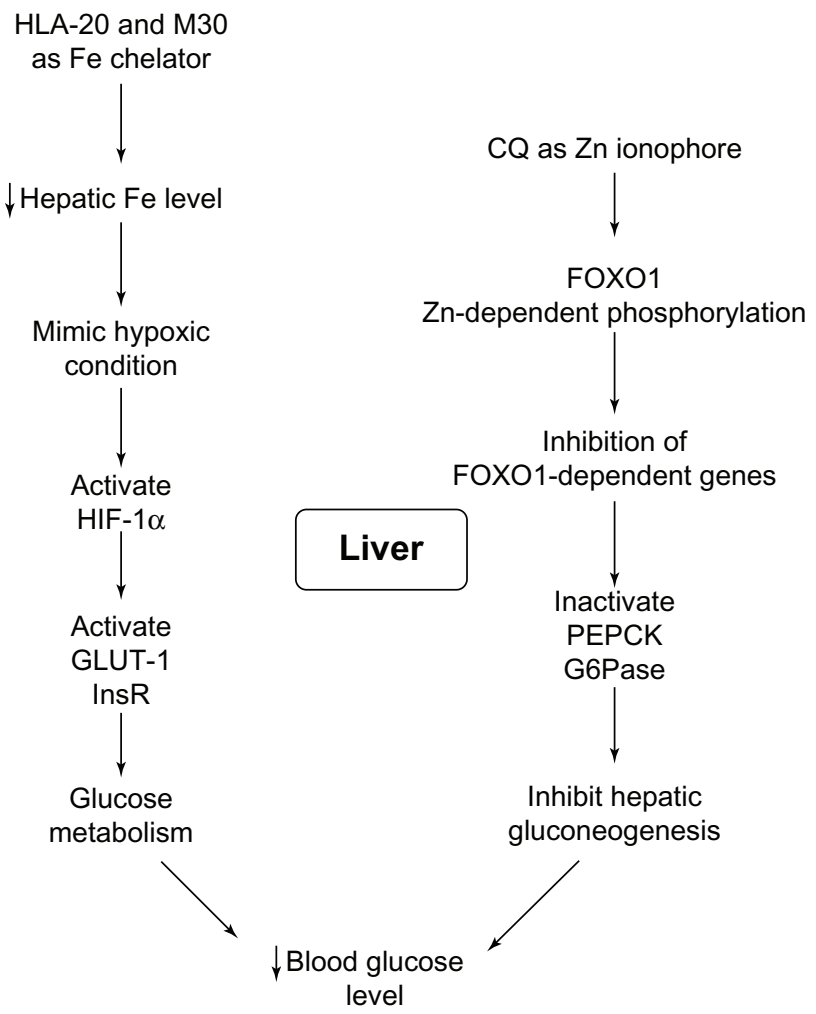

Figure 20 Liver functions on controlling glucose metabolism and antidiabetic actions of 8-hydroxyquinoline derivatives.

Abbreviations: CQ, clioquinol; FOXOI, forkhead box protein OI; G6Pase, glucose-6-phosphatase; GLUT-I, glucose transporter; HIF-I $\alpha$, hypoxia inducible factor; HLA-20, 5-((4-(prop-2-ynyl)piperazin-I-yl)methyl)quinolin-8-ol; InsR, insulin receptor; M30, 5-((methyl(prop-2-ynyl)amino)methyl)quinolin-8-ol; PEPCK phosphoenolpyruvate carboxykinase. 
Table I Brief review of 8-hydroxyquinoline $(8 \mathrm{HQ})$ and its derivatives

$8 \mathrm{HQ}$ is a lipophilic compound with diverse bioactivities which are exerted via its chelating ability.

lonophore is a subset of metal-binding compounds which are capable of transferring multiple metal ions across biological membranes, either in or out of cells.

\section{Antineurodegenerative activity}

- $8 \mathrm{HQ}$ derivatives are small lipophilic compounds that are capable of entering the blood-brain barrier into the target site in the brain.

- As selective chelator to certain types of metal ions, $8 \mathrm{HQ}$ derivatives decrease neurotoxicity caused by metal-protein interaction.

- As antioxidant, $8 \mathrm{HQ}$ derivatives reduce ROS formation and oxidative damage to the brain.

Anticancer activity

- $\mathrm{Fe}$ is a redox-reactive metal ion that generates ROS and serves as nutrient for cancer cell growth.

- $8 \mathrm{HQ}$ is capable of forming complexes with metal that incorporated in enzymes required for DNA synthesis. This results in an antiproliferative effect of the compound.

- 8HQ-Fe lipophilic complex intercalates with DNA strands and causes massive DNA damage leading to cancer cell apoptosis.

- $\mathrm{Cu}$ is a cofactor for tumor angiogenesis and is found in relatively high levels in tissue and serum of cancer patients compared to normal subjects. This indicates the potential of using $\mathrm{Cu}$ as a selective target for cancer treatment.

- CQ acts as $\mathrm{Cu}$ ionophore to transport $\mathrm{Cu}$ into cells where it exerts activity. CQ-Cu complex interacts with electron donor groups located outside of proteasome leading to proteasome inhibition and apoptosis.

Antimicrobial activity

- $8 \mathrm{HQ}$ derivatives were reported to exert antimicrobial activities against a variety of microorganisms such as Mycobacterium tuberculosis, Escherichia coli, Staphylococcus aureus (including MRSA), Streptococcus mutans, Candida albicans, HIV, Plasmodium falciparum and Toxoplasma gondii.

Antioxidant activity

- $8 \mathrm{HQ}$ and its derivatives are potent antioxidants.

- 8HQ metal complexes were reported with improved antioxidant activity (SOD assay) compared to free ligand $8 \mathrm{HQ}$.

Anti-inflammatory activity

- $8 \mathrm{HQ}$ inhibits nitric oxide production at transcriptional level via inhibition of NF- $\kappa B$ and $C / E B P \beta D N A$ binding.

Transportation of $\mathbf{P b}$ across red blood cells (RBC)

- Long-term exposure to Pb-containing environment causes lead poisoning. Excessive $\mathrm{Pb}$ ions are sequestered in $\mathrm{RBC}$ and affect Zn-containing RBC enzyme leading to cardiovascular risk.

- Most of the clinically used $\mathrm{Pb}$ chelators are not capable of passing across erythrocyte membrane thereby giving only a short period of therapeutic benefits.

- $\mathrm{CQ}$ acts as $\mathrm{Zn}$ ionophore to increase $\mathrm{Zn}$ intracellular level of RBC. Additional $\mathrm{Zn}$ ion is believed to displace $\mathrm{Pb}$ from enzyme and promote $\mathrm{Pb}$ escape into the extracellular space, where it is effectively chelated by $\mathrm{Pb}$ chelators.

- $\mathrm{CQ}$ and other classes of $\mathrm{Zn}$ ionophore are considered to be promising compounds that should be further developed as combined agents with $\mathrm{Pb}$ chelators to improve treatment outcome.

Building block for artificial carbohydrate receptors

- 8HQ-based receptors exhibit high affinity to $\beta$-galactoside thereby indicating their potential as artificial carbohydrate receptors.

(Continued)
Table I (Continued)

Potential antidiabetic activity

- FOXO proteins are crucial regulators against oxidative stress conditions.

- Nuclear FOXOI is important for the expression of many downstream effector genes, which function to maintain glucose homeostasis and protect against oxidative stress condition.

- FOXOI exclusion from the nucleus activates $\beta$-cell proliferation and insulin production; however, this also reduces oxidative stress resistance leading to $\beta$-cell apoptosis.

- A compound is considered diabetogenic if it has the ability to harm $\beta$-cells, including decreasing antioxidant defenses and activating $\beta$-cell proliferation leading to $\beta$-cell apoptosis.

- $8 \mathrm{HQ}$ has been reported as a diabetogenic agent due to its ability to induce $\mathrm{Zn}$-dependent FOXOI phosphorylation via action of the $\mathrm{Zn}$ ionophore as well as its acidity caused by release of $\mathrm{H}^{+}$from $\mathrm{OH}$ groups. These phenomena lead to $\beta$-cell apoptosis, which affects insulin production and control of blood glucose.

- It was suggested that the ideal antidiabetic agent should be capable of decreasing blood glucose level via induction of FOXO I phosphorylation as well as minimizing $\beta$-cell damage.

- $\mathrm{CQ}$ is considered a potential antidiabetic agent. It has the ability to induce FOXOI phosphorylation without diabetogenic effect. It was suggested that increased lipophilic, electronic, and steric effects may be involved in the lack of diabetogenicity.

- 8HQ-based antineurodegenerative agents such as M30 and HLA-20 have beneficial effects on controlling blood glucose via Fe chelation. Glucose metabolism is directly controlled by hepatic factors. The decreased hepatic Fe levels can mimic hypoxic conditions that results in lower blood glucose level.

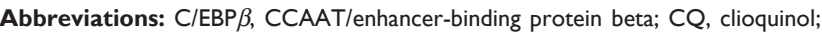
HIV, Human immunodeficiency virus; MRSA, methicillin-resistant Staphylococcus aureus; $\mathrm{NF}-\mathrm{KB}$, nuclear factor kappa-light-chain-enhancer of activated $\mathrm{B}$ cells; ROS, reactive oxygen species; SOD, superoxide dismutase; HQ, hydroxyquinoline; FOXO, forkhead box protein.

$\mathrm{SO}_{3} \mathrm{H}$ ) and polar amino groups were investigated in vitro. ${ }^{190}$ The results showed that $8 \mathrm{HQ}$ and 8-hydroxyquinaldine (Figure 19A) displayed diabetogenic effects and strongly induced FOXO1 phosphorylation in the presence of $\mathrm{Zn}^{2+}$. However, all $8 \mathrm{HQ}$ derivatives with substituents at $\mathrm{C}-2\left(\mathrm{CO}_{2} \mathrm{H}\right)$ and $\mathrm{C}-5\left(\mathrm{SO}_{3} \mathrm{H}\right)$ (Figure 19B) positions showed no diabetogenicity, and no induction of FOXO1 phosphorylation. This could be attributed to anionic charge groups $\left(\mathrm{CO}_{2}^{-}\right.$and $\mathrm{SO}_{3}^{-}$) that inhibited their penetration into the cell and specific compartments. Furthermore, 2HQ and 4HQ (Figure 19C) displayed no diabetogenic effects and no induction of FOXO1 phosphorylation. This suggested that the $\mathrm{OH}$ group in the $\mathrm{C}-8$ position on the quinoline ring was crucial for the observed diabetogenic effect. Interestingly, CQ (Figure 19D), a derivative of 8HQ-bearing substitutions with hydrophobic groups at C-5 (chlorine) and C-7 (iodine) positions induced FOXO1 phosphorylation without diabetogenic effects. The phosphorylation of FOXO1 arises from its CQ property as the 
Table 2 Bioactivities and specific mechanisms of 8-hydroxyquinoline (8HQ) and its derivatives

\begin{tabular}{|c|c|c|}
\hline Action & Activity & Mechanism \\
\hline \multirow[t]{5}{*}{ Cu chelator } & Antineurodegenerative & Reduces neurotoxicity caused by metal-protein interaction \\
\hline & Anticancer & Inhibits tumor growth and metastasis by antiangiogenesis \\
\hline & & Induces apoptosis by inactivation of SODI enzyme \\
\hline & Antimicrobial and antiparasitic & Inhibits microbial enzymes \\
\hline & Antioxidant & Mimics SOD activity \\
\hline \multirow[t]{6}{*}{ Fe chelator } & Antineurodegenerative & Reduces neurotoxicity caused by metal-protein interaction \\
\hline & Anticancer & Inhibits tumor growth by antiproliferation \\
\hline & & Inhibits enzymes required for DNA synthesis \\
\hline & & Induces apoptosis by DNA intercalation of 8HQ-Fe complex \\
\hline & Antimicrobial and antiparasitic & Inhibits microbial enzymes \\
\hline & Antidiabetic & Alters glucose metabolism via expression of hepatic factors \\
\hline \multirow[t]{2}{*}{ Zn chelator } & Antineurodegenerative & Allows degradation of misfolded proteins \\
\hline & & Reduces neurotoxicity caused by metal-protein interaction \\
\hline \multirow[t]{4}{*}{ Cu ionophore } & Antineurodegenerative & Restores brain metal homeostasis by redistribution of intracellular \\
\hline & & $\mathrm{Cu}$ ions and delivery of $\mathrm{Cu}$ ions to the brain areas where they are depleted \\
\hline & & Activates protective signaling cascades \\
\hline & Anticancer & Inhibits apoptosis via proteasome inhibition \\
\hline \multirow[t]{7}{*}{ Zn ionophore } & Antineurodegenerative & Restores brain metal homeostasis by redistribution of intracellular \\
\hline & & $\mathrm{Zn}$ ions and delivery of $\mathrm{Zn}$ ions to brain areas where they are depleted \\
\hline & Anticancer & Induces apoptosis via lysosomal disruption and NF- $k B$ inactivation \\
\hline & Antidiabetic & Increases insulin production and inhibits hepatic enzymes required for \\
\hline & & gluconeogenesis via induction of $\mathrm{Zn}$-dependent FOXOI phosphorylation \\
\hline & $\mathrm{Pb}$ poisoning treatment & Improves effect of $\mathrm{Pb}$ chelators by promoting $\mathrm{Pb}$ escape from red blood \\
\hline & & cells into extracellular space \\
\hline
\end{tabular}

Abbreviations: NF- $\mathrm{KB}$, nuclear factor kappa-light-chain-enhancer of activated B cells; SOD, superoxide dismutase; FOXO, forkhead box protein.

$\mathrm{Zn}$ ionophore. It was suggested that increased hydrophobicity alone is unlikely to account for the nondiabetogenicity of CQ; however, other factors such as electronic and steric effects may be involved in the lack of diabetogenic effects.

According to IIS regulatory roles on glucose homeostasis, an ideal antidiabetic agent should be capable of inducing FOXO1 phosphorylation as well as minimizing oxidative damage to $\beta$-cells. Recent studies suggested that the scope of drug design may focus on small Zn-binding FOXO1 regulators targeting lipophilic compounds that do not release $\mathrm{H}^{+}$ after Zn-binding. ${ }^{191}$ Therefore, CQ is a potential candidate for DM treatment. ${ }^{190}$

Antidiabetic activity of other 8HQ derivatives, such as M30 and HLA-20, have been reported to function through different mechanisms. ${ }^{34,152}$ The liver is the center of Fe homeostasis, and hepatic enzymes are found to be key regulators of hepatic gluconeogenesis. ${ }^{34}$ Glucose metabolism is directly controlled by hepatic factors that in turn are regulated by Fe levels, as is the case for the glucose transporter and the insulin receptor. ${ }^{34}$ As Fe chelators, M30 and HLA-20 generate low levels of Fe, thereby mimicking hypoxic conditions. ${ }^{34}$ Such conditions increase the expression of $\mathrm{Fe} / \mathrm{O}_{2}^{-}$regulated hypoxia inducible factor. The activation of hypoxia inducible factor leads to the expression of downstream effector genes including the glucose transporter and the insulin receptor, which consequently causes lower blood glucose levels ${ }^{34}$ as shown in Figure 20.

In addition, both compounds exhibit protective effects against oxidative damage to $\beta$-cells. ${ }^{152} \mathrm{~A}$ study on pancreatic $\beta$-cell lines indicated that cytoprotective effects of HLA-20 and M30 arise from combined actions ${ }^{152}$ in which they act as Fe chelators. M30 and HLA-20 directly decrease ROS formation by inhibiting the Fenton reaction as well as indirectly increasing catalase activity, ${ }^{152}$ possibly by maintaining nuclear FOXO1 levels. ${ }^{184}$ Furthermore, both compounds promote antiapoptotic effects against $\mathrm{H}_{2} \mathrm{O}_{2}$ stress-induced mitochondrial dysfunction. ${ }^{152}$ Mitochondria are known to play important roles on cell cycle regulation, ${ }^{152}$ and their dysfunction is a critical event leading to cell apoptosis. ${ }^{152} \mathrm{M} 30$ and HLA-20 exert antiapoptotic effects by maintenance of a mitochondrial factor called $\Delta \psi \mathrm{M}$, which is necessary for mitochondria survival. ${ }^{152}$

Due to IIS and the FOXO1 phosphorylation inductive ability and significant cytoprotective effects, $8 \mathrm{HQ}$ and its derivatives could be a promising class of compound that merits further development for the treatment of DM. ${ }^{152,190}$

\section{Conclusion}

Metal imbalance plays a crucial role in the etiology of many diseases that affect quality of life. The objectives of treatment 
are not only aimed at restoring metal balance but also at minimizing cellular damage. 8HQ and its derivatives possess diverse pharmacological and biological activities, which are a result of their chelating ability (Table 1). Interestingly, such bioactivities originate from multiple mechanisms (Table 2). These mechanisms of actions function in restoring metal homeostasis as well as promoting protective effects. Therefore, 8HQ and its derivatives are considered as promising candidates that should be further developed as therapeutics for many diseases.

\section{Acknowledgments}

This project was supported by the Office of the Higher Education Commission, Mahidol University, under the National Research Universities Initiative and Annual Governmental Grant of Mahidol University (2556-2558 BE). VP thanks Chanin Nantasenamat for the proofreading of this manuscript.

\section{Disclosure}

The authors report no conflicts of interest in this work.

\section{References}

1. Short BR, Vargas MA, Thomas JC, O'Hanlon S, Enright MC. In vitro activity of a novel compound, the metal ion chelating agent $\mathrm{AQ}^{+}$, against clinical isolates of Staphylococcus aureus. J Antimicrob Chemother. 2006;57(1):104-109.

2. Albrecht M, Fiege M, Osetska O. 8-Hydroxyquinolines in metallosupramolecular chemistry. Coord Chem Rev. 2008;252(8-9):812-824.

3. Budimir A. Metal ions, Alzheimer's disease and chelation therapy. Acta Pharm. 2011;61(1):1-14.

4. Crichton RR, Dexter DT, Ward RJ. Metal based neurodegenerative diseases-From molecular mechanisms to therapeutic strategies. Coord Chem Rev. 2008;252(10-11):1189-1199.

5. Vanparia SF, Patel TS, Sojitra NA, et al. Synthesis, characterization and antimicrobial study of novel 4-\{[(8-Hydroxyquinolin-5-yl) methyl]amino benzenesulfonamide and its oxinates. Acta Chim Slov. 2010;57(3):600-667.

6. Rubbo SD, Albert A, Gibson MI. The influence of chemical constitution on antibacterial activity. V. The antibacterial action of 8-hydroxyquinoline (oxine). Br J Exp Pathol. 1950;31(3):425-441.

7. Crichton RR, Dexter DT, Ward RJ. Brain iron metabolism and its perturbation in neurological diseases. J Neural Transm. 2011;118(3):301-314.

8. Tõugu V, Palumaa P. Coordination of zinc ions to the key proteins of neurodegenerative diseases: A $\beta$, APP, $\alpha$-synuclein and PrP. Coord Chem Rev. 2012;256(19-20):2219-2224.

9. Bush AI. The metallobiology of Alzheimer's disease. Trends Neurosci. 2003;26(4):207-214.

10. Bush AI, Tanzi RE. Therapeutics for Alzheimer's disease based on the metal hypothesis. Neurotherapeutics. 2008;5(3):421-432.

11. Gaeta A, Hider RC. The crucial role of metal ions in neurodegeneration: the basis for a promising therapeutic strategy. $\mathrm{Br} J$ Pharmacol. 2005;146(8):1041-1059.

12. Zatta P, Drago D, Bolognin S, Sensi SL. Alzheimer's disease, metal ions and metal homeostatic therapy. Trends Pharmacol Sci. 2009;30(7): $346-355$.
13. Perez LR, Franz KJ. Minding metals: tailoring multifunctional chelating agents for neurodegenerative disease. Dalton Trans. 2010;39(9): 2177-2187.

14. Crouch PJ, Barnham KJ. Therapeutic redistribution of metal ions to treat Alzheimer's disease. Acc Chem Res. 2012;45(9):1604-1611.

15. Zheng $\mathrm{H}$, Gal S, Weiner LM, et al. Novel multifunctional neuroprotective iron chelator-monoamine oxidase inhibitor drugs for neurodegenerative diseases: in vitro studies on antioxidant activity, prevention of lipid peroxide formation and monoamine oxidase inhibition. J Neurochem. 2005;95(1):68-78.

16. Kaur D, Yantiri F, Rajagopalan S, et al. Genetic or pharmacological iron chelation prevents MPTP-induced neurotoxicity in vivo: a novel therapy for Parkinson's disease. Neuron. 2003;37(6):899-909.

17. Zheng H, Youdim MB, Weiner LM, Fridkin M. Synthesis and evaluation of peptidic metal chelators for neuroprotection in neurodegenerative diseases. J Pept Res. 2005;66(4):190-203.

18. Deraeve C, Pitié M, Mazarguil H, Meunier B. Bis-8-hydroxyquinoline ligands as potential anti-Alzheimer agents. New J Chem. 2007;31(2): 193-195.

19. Ritchie CW, Bush AI, Mackinnon A, et al. Metal-protein attenuation with iodochlorhydroxyquin (clioquinol) targeting Abeta amyloid deposition and toxicity in Alzheimer disease: a pilot phase 2 clinical trial. Arch Neurol. 2003;60(12):1685-1691.

20. Cherny RA, Atwood CS, Xilinas ME, et al. Treatment with a copper-zinc chelator markedly and rapidly inhibits beta-amyloid accumulation in Alzheimer's disease transgenic mice. Neuron. 2001;30(3):665-676.

21. Tateishi J. Subacute myelo-optico-neuropathy: clioquinol intoxication in humans and animals. Neuropathology. 2000;20 Suppl: S20-S24.

22. Yassin MS, Ekblom J, Xilinas M, Gottfries CG, Oreland L. Changes in uptake of vitamin $\mathrm{B}(12)$ and trace metals in brains of mice treated with clioquinol. J Neurol Sci. 2000;173(1):40-44.

23. Budimir A, Humbert N, Elhabiri M, Osinska I, Biruš M, Albrecht-Gary AM. Hydroxyquinoline based binders: promising ligands for chelatotherapy? J Inorg Biochem. 2011;105(3):490-496.

24. LeVine H, Ding Q, Walker JA, Voss RS, Augelli-Szafran CE. Clioquinol and other hydroxyquinoline derivatives inhibit Abeta (1-42) oligomer assembly. Neurosci Lett. 2009;465(1):99-103.

25. White AR, Du T, Laughton KM, et al. Degradation of the Alzheimer disease amyloid beta-peptide by metal-dependent up-regulation of metalloprotease activity. J Biol Chem. 2006;281(26):17670-17680.

26. Adlard PA, Cherny RA, Finkelstein DI, et al. Rapid restoration of cognition in Alzheimer's transgenic mice with 8-hydroxy quinoline analogs is associated with decreased interstitial Abeta. Neuron. 2008;59(1):43-55.

27. Crouch PJ, Savva MS, Hung LW, et al. The Alzheimer's therapeutic PBT2 promotes amyloid- $\beta$ degradation and GSK3 phosphorylation via a metal chaperone activity. J Neurochem. 2011;119(1):220-230.

28. Adlard PA, Bica L, White AR, et al. Metal ionophore treatment restores dendritic spine density and synaptic protein levels in a mouse model of Alzheimer's disease. PLoS One. 2011;6(3):e17669.

29. Lannfelt L, Blennow K, Zetterberg H, et al; PBT2-201-EURO study group. Safety, efficacy, and biomarker findings of PBT2 in targeting Abeta as a modifying therapy for Alzheimer's disease: a phase IIa, double-blind, randomised, placebo-controlled trial. Lancet Neurol. 2008;7(9):779-786.

30. Faux NG, Ritchie CW, Gunn A, et al. PBT2 rapidly Improves cognition in Alzheimer's disease: additional Phase II analyses. JAlzheimers Dis. 2010;20(2):509-516.

31. Crouch PJ, Tew DJ, Du T, et al. Restored degradation of the Alzheimer's amyloid-beta peptide by targeting amyloid formation. $J$ Neurochem. 2009;108(5):1198-1207.

32. Gal S, Fridkin M, Amit T, Zheng H, Youdim MBH. M30, a novel multifunctional neuroprotective drug with potent iron chelating and brain selective monoamine oxidase-ab inhibitory activity for Parkinson's disease. J Neural Transm Suppl. 2006;(70):447-456. 
33. Kasarskis EJ, Tandon L, Lovell MA, Ehmann WD. Aluminum, calcium, and iron in the spinal cord of patients with sporadic amyotrophic lateral sclerosis using laser microprobe mass spectroscopy: a preliminary study. J Neurol Sci. 1995;130(2):203-208.

34. Pollak Y, Mechlovich D, Amit T, et al. Effects of novel neuroprotective and neurorestorative multifunctional drugs on iron chelation and glucose metabolism. J Neural Transm. 2013;120(1):37-48.

35. Riederer P, Sofic E, Rausch WD, et al. Transition metals, ferritin, glutathione, and ascorbic acid in parkinsonian brains. J Neurochem. 1989;52(2):515-520.

36. Paris I, Martinez-Alvarado P, Cárdenas S, et al. Dopamine-dependent iron toxicity in cells derived from rat hypothalamus. Chem Res Toxicol. 2005;18(3):415-419.

37. Zheng H, Weiner LM, Bar-Am O, et al. Design, synthesis, and evaluation of novel bifunctional iron-chelators as potential agents for neuroprotection in Alzheimer's, Parkinson's, and other neurodegenerative diseases. Bioorg Med Chem. 2005;13(3):773-783.

38. Avramovich-Tirosh Y, Amit T, Bar-Am O, Zheng H, Fridkin M, Youdim MB. Therapeutic targets and potential of the novel brainpermeable multifunctional iron chelator-monoamine oxidase inhibitor drug, M-30, for the treatment of Alzheimer's disease. J Neurochem. 2007;100(2):490-502.

39. Avramovich-Tirosh Y, Bar-Am O, Amit T, Youdim MB, Weinreb O. Up-regulation of hypoxia-inducible factor (HIF)-1 $\alpha$ and HIF-target genes in cortical neurons by the novel multifunctional iron chelator anti-Alzheimer drug, M30. Curr Alzheimer Res. 2010;7(4):300-306.

40. Kupershmidt L, Weinreb O, Amit T, Mandel S, Carri MT, Youdim MB. Neuroprotective and neuritogenic activities of novel multimodal ironchelating drugs in motor-neuron-like NSC-34 cells and transgenic mouse model of amyotrophic lateral sclerosis. FASEB J. 2009;23(11): 3766-3779.

41. Weinreb O, Mandel S, Bar-Am O, Amit T. Iron-chelating backbone coupled with monoamine oxidase inhibitory moiety as novel pluripotential therapeutic agents for Alzheimer's disease: a tribute to Moussa Youdim. J Neural Transm. 2011;118(3):479-492.

42. Youdim MB, Weinstock M. Therapeutic applications of selective and non-selective inhibitors of monoamine oxidase A and B that do not cause significant tyramine potentiation. Neurotoxicology. 2004;25(1-2): 243-250.

43. Stevens RG, Kalkwarf DR. Iron, radiation, and cancer. Environ Health Perspect. 1990;87:291-300.

44. Brem S. Angiogenesis and cancer control: from concept to therapeutic trial. Cancer Control. 1999;6(5):436-458.

45. Brewer GJ. Copper control as an antiangiogenic anticancer therapy: lessons from treating Wilson's disease. Exp Biol Med (Maywood). 2001;226(7):665-673.

46. Theophanides T, Anastassopoulou J. Copper and carcinogenesis. Crit Rev Oncol Hematol. 2002;42(1):57-64.

47. Daniel KG, Harbach RH, Guida WC, Dou QP. Copper storage diseases: Menkes, Wilsons, and cancer. Front Biosci. 2004;9:2652-2662.

48. Gupte A, Mumper RJ. Elevated copper and oxidative stress in cancer cells as a target for cancer treatment. Cancer Treat Rev. 2009;35(1): 32-46.

49. Andrews NC. Disorders of iron metabolism. N Engl J Med. 1999; 341(26):1986-1995.

50. Le NT, Richardson DR. The role of iron in cell cycle progression and the proliferation of neoplastic cells. Biochim Biophys Acta. 2002;1603(1): 31-46.

51. Halliwell B, Gutteridge JM, Cross CE. Free radicals, antioxidants, and human disease: where are we now? J Lab Clin Med. 1992;119(6): 598-620.

52. Cerutti PA. Oxy-radicals and cancer. Lancet. 1994;344(8926): $862-863$

53. Leanderson P, Tagesson C. Rapid and sensitive detection of hydroxyl radicals formed by activated neutrophils in the presence of chelated iron: hydroxylation of deoxyguanosine to 8-hydroxydeoxyguanosine. Agents Actions. 1992;36(1-2):50-57.
54. Leanderson P, Tagesson C. Iron bound to the lipophilic iron chelator, 8-hydroxyquinoline, causes DNA strand breakage in cultured lung cells. Carcinogenesis. 1996;17(3):545-550.

55. Jonas SK, Riley PA. The effect of ligands on the uptake of iron by cells in culture. Cell Biochem Funct. 1991;9(4):245-253.

56. Schraufstatter IU, Hinshaw DB, Hyslop PA, Spragg RG, Cochrane CG. Oxidant injury of cells. DNA strand-breaks activate polyadenosine diphosphate-ribose polymerase and lead to depletion of nicotinamide adenine dinucleotide. J Clin Invest. 1986;77(4):1312-1320.

57. Zhou ZH, Ando S, Furutsuka D, Ikebe M. Characterization of $\mathrm{Ca} 2+$ / calmodulin-dependent protein kinase II from smooth muscle. Biochem J 1995;310(Pt 2):517-525.

58. Hecht SM. DNA strand scission by activated bleomycin group antibiotics. Fed Proc. 1986;45(12):2784-2791.

59. Shaw AY, Chang CY, Hsu MY, et al. Synthesis and structure-activity relationship study of 8-hydroxyquinoline-derived Mannich bases as anticancer agents. Eur J Med Chem. 2010;45(7):2860-2867.

60. Lescoat G, Léonce S, Pierré A, Gouffier L, Gaboriau F. Antiproliferative and iron chelating efficiency of the new bis-8-hydroxyquinoline benzylamine chelator S1 in hepatocyte cultures. Chem Biol Interact. 2012;195(2):165-172.

61. Moor EC. In methods in enzymology. In: Colowick SP, Kaplan ND, editors. Method in Enzymology. New York, NY: Academic; 1967; (12 Pt A): 155 .

62. Yamato M, Hashigaki K, Yasumoto Y, et al. Synthesis and antitumor activity of tropolone derivatives. 6. Structure-activity relationships of antitumor-active tropolone and 8-hydroxyquinoline derivatives. $J \mathrm{Med}$ Chem. 1987;30(10):1897-1900.

63. Prachayasittikul S, Worachartcheewan A, Pingaew R, et al. Metal complexes of uracil derivatives with cytotoxicity and superoxide scavenging activity. Lett Drug Des Dis. 2012;9(3):282-287.

64. Boerner LJ, Zaleski JM. Metal complex-DNA interactions: from transcription inhibition to photoactivated cleavage. Curr Opin Chem Biol. 2005;9(2):135-144.

65. Colak A, Terzi Ü, Col M, et al. DNA binding, antioxidant and antimicrobial activities of homo- and heteronuclear copper(II) and nickel(II) complexes with new oxime-type ligands. Eur J Med Chem. 2010;45(11): 5169-5175.

66. Mathur S, Tabassum S. New homodi-and heterotrinuclear metal complexes of Schiff base compartmental ligand: Interaction studies of copper complexes with calf thymus DNA. Cent Eur J Chem. 2006;4(3): $502-522$.

67. Cowan JA. Chemical nucleases. Curr Opin Chem Biol. 2001;5(6): 634-642.

68. Tan J, Wang B, Zhu L. DNA binding, cytotoxicity, apoptotic inducing activity, and molecular modeling study of quercetin zinc(II) complex. Bioorg Med Chem. 2009;17(2):614-620.

69. Dixit RB, Patel TS, Vanparia SF, Kunjadiya AP, Keharia HR, Dixit BC. DNA-binding interaction studies of microwave assisted synthesized sulfonamide substituted 8-hydroxyquinoline derivatives. Sci Pharm. 2011;79(2):293-308.

70. Xu H, Zheng KC, Chen Y, et al. Effects of ligand planarity on the interaction of polypyridyl Ru(II) complexes with DNA. Dalton Trans. 2003;11:2260-2268.

71. Delaney S, Pascaly M, Bhattacharya PK, Han K, Barton JK. Oxidative damage by ruthenium complexes containing the dipyridophenazine ligand or its derivatives: a focus on intercalation. Inorg Chem. 2002;41(7):1966-1974.

72. Siddiqi ZA, Khalid M, Kumar S, Shahid M, Noor S. Antimicrobial and SOD activities of novel transition metal complexes of pyridine2,6-dicarboxylic acid containing 4-picoline as auxiliary ligand. Eur $J$ Med Chem. 2010;45(1):264-269.

73. Serbest K, Colak A, Güner S, Karaböcek S, Kormali F. Copper(II)manganese(II) complexes of 3,3'-(1,3-propanediyldiimine)bis-(3methyl-2-butanone)dioxime with superoxide dismutase-like activity. Transit Metal Chem. 2001;26(6):625-629. 
74. Saheki T, Ueda A, Hosoya M, et al. Qualitative and quantitative abnormalities of argininosuccinate synthetase in citrullinemia. Clin Chim Acta. 1981;109(3):325-335.

75. Nayak SB, Bhat VR, Upadhyay D, Udupa SL. Copper and ceruloplasmin status in serum of prostate and colon cancer patients. Indian J Physiol Pharmacol. 2003;47(1):108-110.

76. Huang YL, Sheu JY, Lin TH. Association between oxidative stress and changes of trace elements in patients with breast cancer. Clin Biochem. 1999;32(2):131-136.

77. Rizk SL, Sky-Peck HH. Comparison between concentrations of trace elements in normal and neoplastic human breast tissue. Cancer Res. 1984;44(11):5390-5394.

78. Turecký L, Kalina P, Uhliková E, Námerová S, Krizko J. Serum ceruloplasmin and copper levels in patients with primary brain tumors. Klin Wochenschr. 1984;62(4):187-189.

79. Chen D, Cui QC, Yang H, et al. Clioquinol, a therapeutic agent for Alzheimer's disease, has proteasome-inhibitory, androgen receptorsuppressing, apoptosis-inducing, and antitumor activities in human prostate cancer cells and xenografts. Cancer Res. 2007;67(4):1636-1644.

80. Ding WQ, Lind SE. Metal ionophores - an emerging class of anticancer drugs. IUBMB Life. 2009;61(11):1013-1018.

81. Daniel KG, Chen D, Orlu S, Cui QC, Miller FR, Dou QP. Clioquinol and pyrrolidine dithiocarbamate complex with copper to form proteasome inhibitors and apoptosis inducers in human breast cancer cells. Breast Cancer Res. 2005;7(6):R897-R908.

82. Mao X, Li X, Sprangers R, et al. Clioquinol inhibits the proteasome and displays preclinical activity in leukemia and myeloma. Leukemia. 2009;23(3):585-590.

83. Lind SE, Park JS, Drexler JW. Pyrithione and 8-hydroxyquinolines transport lead across erythrocyte membranes. Transl Res. 2009;154(3): $153-159$.

84. Ding WQ, Liu B, Vaught JL, Yamauchi H, Lind SE. Anticancer activity of the antibiotic clioquinol. Cancer Res. 2005;65(8):3389-3395.

85. Yu H, Zhou Y, Lind SE, Ding WQ. Clioquinol targets zinc to lysosomes in human cancer cells. Biochem J. 2009;417(1):133-139.

86. Andersson DA, Gentry C, Moss S, Bevan S. Clioquinol and pyrithione activate TRPA1 by increasing intracellular Zn2+. Proc Natl Acad Sci U S A. 2009;106(20):8374-8379.

87. Ruschak AM, Slassi M, Kay LE, Schimmer AD. Novel proteasome inhibitors to overcome bortezomib resistance. J Natl Cancer Inst. 2011;103(13):1007-1017.

88. Geraki K, Farquharson MJ, Bradley DA. Concentrations of Fe, $\mathrm{Cu}$ and $\mathrm{Zn}$ in breast tissue: a synchrotron XRF study. Phys Med Biol. 2002;47(13):2327-2339.

89. Dìez M, Cerdàn FJ, Arroyo M, Balibrea JL. Use of the copper/zinc ratio in the diagnosis of lung cancer. Cancer. 1989;63(4):726-730.

90. Yoshida D, Ikeda Y, Nakazawa S. Quantitative analysis of copper, zinc and copper/zinc ratio in selected human brain tumors. J Neurooncol. 1993;16(2):109-115

91. Daniel KG, Gupta P, Harbach RH, Guida WC, Dou QP. Organic copper complexes as a new class of proteasome inhibitors and apoptosis inducers in human cancer cells. Biochem Pharmacol. 2004;67(6):1139-1151.

92. Dorkin TJ, Neal DE. Basic science aspects of prostate cancer. Semin Cancer Biol. 1997;8(1):21-27.

93. Arnold JT, Isaacs JT. Mechanisms involved in the progression of androgen-independent prostate cancers: it is not only the cancer cell's fault. Endocr Relat Cancer. 2002;9(1):61-73.

94. Yu H, Lou JR, Ding WQ. Clioquinol independently targets NF-kappaB and lysosome pathways in human cancer cells. Anticancer Res. 2010;30(6):2087-2092.

95. Ding WQ, Yu HJ, Lind SE. Zinc-binding compounds induce cancer cell death via distinct modes of action. Cancer Lett. 2008;271(2):251-259.

96. Jiang H, Taggart JE, Zhang X, Benbrook DM, Lind SE, Ding WQ. Nitroxoline (8-hydroxy-5-nitroquinoline) is more a potent anti-cancer agent than clioquinol (5-chloro-7-iodo-8-quinoline). Cancer Lett. 2011;312(1):11-17.
97. Arbiser JL, Kraeft SK, van Leeuwen R, et al. Clioquinol-zinc chelate: a candidate causative agent of subacute myelo-optic neuropathy. $\mathrm{Mol}$ Med. 1998;4(10):665-670.

98. American Academy of Pediatrics Committee on Drugs: Clioquinol (iodochlorhydroxyquin, vioform) and iodoquinol (diiodohydroxyquin): blindness and neuropathy. Pediatrics. 1990;86(5):797-798.

99. Oliveri V, Giuffrida ML, Vecchio G, Aiello C, Viale M. Gluconjugates of 8-hydroxyquinolines as potential anti-cancer prodrugs. Dalton Trans. 2012;41(15):4530-4535.

100. Kawamura T, Kusakabe T, Sugino T, et al. Expression of glucose transporter-1 in human gastric carcinoma: association with tumor aggressiveness, metastasis, and patient survival. Cancer. 2001;92(3):634-641.

101. Arafa HM. Possible contribution of beta-glycosidases and caspases in the cytotoxicity of novel glycoconjugates in colon cancer cells. Invest New Drugs. 2010;28(3):306-317.

102. Pavlov A, Takuchev N, Georgieva N. Drug design by regression analyses of newly synthesized derivatives of 8-quinolinol. Biotechnol Biotechnol Equip. 2011;26(1):164-169.

103. Jeon JH, Lee CH, Lee HS. Antimicrobial activities of 2-methyl-8hydroxyquinoline and its derivatives against human intestinal bacteria. J Korean Soc Appl Biol Chem. 2009;52(2):202-205.

104. Ahmed SM, Ismail DA. Synthesis and biological activity of 8-hydroxyquinoline and 2-hydroxypyridine quaternary ammonium salts. J Surfact Deterg. 2008;11(3):231-235.

105. Strobl JS, Seibert CW, Li Y, et al. Inhibition of Toxoplasma gondii and Plasmodium falciparum infections in vitro by NSC3852, a redox active antiproliferative and tumor cell differentiation agent. J Parasitol. 2009;95(1):215-223.

106. Scheibel LW, Adler A. Antimalarial activity of selected aromatic chelators. III. 8-Hydroxyquinolines (oxines) substituted in positions 5 and 7, and oxines annelated in position 5,6 by an aromatic ring. $\mathrm{Mol}$ Pharmacol. 1982;22(1):140-144.

107. Madrid PB, Sherrill J, Liou AP, Weisman JL, Derisi JL, Guy RK. Synthesis of ring-substituted 4-aminoquinolines and evaluation of their antimalarial activities. Bioorg Med Chem Lett. 2005;15(4): 1015-1018.

108. Moret V, Dereudre-Bosquet N, Clayette P, et al. Synthesis and antiHIV properties of new hydroxyquinoline-polyamine conjugates on cells infected by HIV-1 LAV and HIV-1 BaL viral strains. Bioorg Med Chem Lett. 2006;16(23):5988-5992.

109. Darby CM, Nathan CF. Killing of non-replicating Mycobacterium tuberculosis by 8-hydroxyquinoline. J Antimicrob Chemother. 2010;65(7):1424-1427.

110. Warner VD, Musto JD, Sane JN, Kim KH, Grunewald GL. Quantitative structure-activity relationships for 5-substituted 8-hydroxyquinolines as inhibitors of dental plaque. J Med Chem. 1977;20(1):92-96.

111. Tanzer JM, Slee AM, Kamay B, Scheer E. Activity of three 8-hydroxyquinoline derivatives against in vitro dental plaque. Antimicrob Agents Chemother. 1978;13(6):1044-1045.

112. Ananthan S, Faaleolea ER, Goldman RC, et al. High-throughput screening for inhibitors of Mycobacterium tuberculosis H37Rv. Tuberculosis (Edinb). 2009;89(5):334-353.

113. Kharadi GJ, Patel JR, Dholakiya BZ. Antituberculosis, antifungal and thermal activity of mixed ligand transition metal complexes. Appl Organomet Chem. 2010;24(11):821-827.

114. Irish D, Eltringham I, Teall A, et al. Control of an outbreak of an epidemic methicillin-resistant Staphylococcus aureus also resistant to mupirocin. J Hosp Infect. 1998;39(1):19-26.

115. Takahashi N. Microbial ecosystem in the oral cavity: metabolic diversity in an ecological niche and its relationship with oral diseases. Proceedings of the International Symposium for Interface Oral Health, Sendai, Japan, 2-3 February 2005; International Congress Series. 2005;1284:103-112.

116. Rathsam C, Eaton RE, Simpson CL, et al. Two-dimensional fluorescence difference gel electrophoretic analysis of Streptococcus mutans biofilms. J Proteome Res. 2005;4(6):2161-2173. 
117. Lemos JA, Abranches J, Burne RA. Responses of cariogenic streptococci to environmental stresses. Curr Issues Mol Biol. 2005;7(1): 95-107.

118. Albert A, Magrath D. The choice of a chelating agent for inactivating trace metals: II. Derivatives of oxine (8-hydroxyquinoline). Biochem.J. 1947;41(4):534-530.

119. Albert A, Gibson MI, Rubbo SD. The influence of chemical constitution on antibacterial activity. VI. The bactericidal action of 8-hydroxyquinoline (oxine). Br J Exp Pathol. 1953;34(2): $119-130$.

120. Anjaneyulu Y, Rao RP, Swamy RY, Eknath A, Rao KN. In vitro antimicrobial-activity studies on the mixed ligand complexes of $\mathrm{Hg}(\mathrm{II})$ with 8-hydroxyquinoline and salicylic acids. Proc Indian Acad Sci (Chem Sci). 1982;91(2):157-163.

121. Srisung S, Suksrichavalit T, Prachayasittikul S, Ruchirawat S, Prachayasittikul V. Antimicrobial activity of 8-hydroxyquinoline and transition metal complexes. Int J Pharmacol. 2013:9(2)170-175.

122. Shen AY, Chen CP, Roffler S. A chelating agent possessing cytotoxicity and antimicrobial activity: 7-morpholinomethyl-8-hydroxyquinoline. Life Sci. 1999;64(9):813-825.

123. Badawi AM, Mohamed MA, Mohamed MZ, Khowdairy MM. Surface and antitumor activity of some novel metal-based cationic surfactants. J Cancer Res Ther. 2007;3(4):198-206.

124. Rohde W, Mikelens P, Jackson J, Blackman J, Whitcher J, Levinson W. Hydroxyquinolines inhibit ribonucleic acid-dependent deoxyribonucleic acid polymerase and inactivate Rous sarcoma virus and herpes simplex virus. Antimicrob Agents Chemother. 1976;10(2): 234-240.

125. Auld DS, Kawaguchi H, Livingston DM, Vallee BL. RNA-dependent DNA polymerase (reverse transcriptase) from avian myeloblastosis virus: a zinc metalloenzyme. Proc Natl Acad Sci U S A. 1974;71(5): 2091-2095.

126. Valenzuela P, Morris RW, Faras A, Levinson W, Rutter WJ. Are all nucleotidyl transferases metalloenzymes? Biochem Biophys Res Commun. 1973;53(3):1036-1041

127. Albert A. Quantitative studies of the avidity of naturally occurring substances for trace metals. III. Pteridines, riboflavin and purines. Biochem J. 1953;54(4):646-654.

128. De Clercq E. Antiviral drug discovery and development: where chemistry meets with biomedicine. Antiviral Res. 2005;67(2):56-75.

129. De Clercq E. HIV-chemotherapy and -prophylaxis: new drugs, leads and approaches. Int J Biochem Cell Biol. 2004;36(9):1800-1822.

130. Hatse S, Princen K, Gerlach LO, et al. Mutation of Asp(171) and Asp(262) of the chemokine receptor CXCR4 impairs its coreceptor function for human immunodeficiency virus-1 entry and abrogates the antagonistic activity of AMD3100. Mol Pharmacol. 2001;60(1): 164-173.

131. Gilles HM. Management of Severe Malaria: A Practical Handbook. 2nd ed. Geneva: World Health Organization; 2000

132. Coatney GR, Cooper WC, Eddy NB, Greengerg J. Survey of antimalarial agents: chemotherapy of Plasmodium gallinaceum infections; toxicity; correlation of structure and action. Public Health Monogr. 1953;9:1-322.

133. De D, Krogstad FM, Cogswell FB, Krogstad DJ. Aminoquinolines that circumvent resistance in Plasmodium falciparum in vitro. Am J Trop Med Hyg. 1996;55(6):579-583.

134. Scheibel LW, Adler A, Trager W. Tetraethylthiuram disulfide (Antabuse) inhibits the human malaria parasite Plasmodium falciparum. Proc Nat Acad Sci U S A. 1979;76(10):5303-5307.

135. Scheibel LW, Adler A. Antimalarial activity of selected aromatic chelators. Mol Pharmacol. 1980;18(2):320-325.

136. Scheibel LW, Adler A. Antimalarial activity of selected aromatic chelators. II. Substituted quinolines and quinoline-N-oxides. Mol Pharmacol. 1981;20(1):218-223.

137. Owens RG. Studies on the nature of fungicidal action. I. Inhibition of sulfhydryl-, amino-, iron-, and copper-dependent enzymes in vitro by fungicides and related compounds. Contr Boyce Thompson Inst. 1953;17(3):221-242.
138. Denton H, Roberts CW, Alexander J, Thong KW, Coombs GH. Enzymes of energy metabolism in the bradyzoites and tachyzoites of Toxoplasma gondii. FEMS Microbiol Lett. 1996;137(1):103-108.

139. McCarthy SM, Davis CD. Prooxidant diet provides protection during murine infection with Toxoplasma gondii. J Parasitol. 2003;89(5): 886-894.

140. Pino P, Foth BJ, Kwok LY, et al. Dual targeting of antioxidant and metabolic enzymes to the mitochondrion and the apicoplast of Toxoplasma gondii. PLoS Pathog. 2007;3(8):e115.

141. Martirosyan A, Leonard S, Shi X, Griffith B, Gannett P, Strobl J. Actions of a histone deacetylase inhibitor NSC3852 (5-nitroso-8quinolinol) link reactive oxygen species to cell differentiation and apoptosis in MCF-7 human mammary tumor cells. J Pharmacol Exp Ther. 2006;317(2):546-552.

142. Henry TR, Wallace KB. Differential mechanisms of cell killing by redox cycling and arylating quinones. Arch Toxicol. 1996;70(8): 482-489.

143. Reis DC, Pinto MC, Souza-Fagundes EM, et al. Investigation on the pharmacological profile of antimony(III) complexes with hydroxyquinoline derivatives: anti-trypanosomal activity and cytotoxicity against human leukemia cell lines. Biometals. 2011;24(4):595-601.

144. Halliwell B, Gutteridge JM. Oxygen toxicity, oxygen radicals, transition metals and disease. Biochem J. 1984;219(1):1-14.

145. Valko M, Morris H, Cronin MT. Metals, toxicity and oxidative stress Curr Med Chem. 2005;12(10):1161-1208.

146. Mau JL, Lin HC, Song SF. Antioxidant properties of several specialty mushrooms. Food Res Int. 2002;35(6):519-526.

147. Roby MHH, Sarhan MA, Selim KAH, Khalel KI. Evaluation of antioxidant activity, total phenols and phenolic compounds in thyme (Thymus vulgaris L.), sage (Salvia officinalis L.), and marjoram (Origanum majorana L.) extracts. Ind Crops Prod. 2013;43: 827-831.

148. Ma L, Liu Z, Zhou B, Yang L, Liu Z. Inhibition of free radical induced oxidative hemolysis of red blood cells by green tea polyphenols. Chin Sci Bull. 2000;45(22):2052-2056.

149. Prachayasittikul V, Prachayasittikul S, Ruchirawat S. High therapeutic potential of Spilanthes acmella: A review. EXCLI J. 2013;12: 291-312.

150. Burton GW, Ingold KU. Vitamin E: application of the principles of physical organic chemistry to the exploration of its structure and function. Acc Chem Res. 1986;19(7):194-201.

151. Spiteller G. Linoleic acid peroxidation - the dominant lipid peroxidation process in low density lipoprotein - and its relationship to chronic diseases. Chem Phys Lipids. 1998;95(2):105-162.

152. Mechlovich D, Amit T, Mandel SA, et al. The novel multifunctional, iron-chelating drugs M30 and HLA20 protect pancreatic beta-cell lines from oxidative stress damage. J Pharmacol Exp Ther. 2010;333(3): 874-882.

153. Fernández-Bachiller MI, Pérez C, González-Muñoz GC, et al. Novel tacrine - 8-hydroxyquinoline hybrids as multifunctional agents for the treatment of Alzheimer's disease, with neuroprotective, cholinergic, antioxidant, and copper-complexing properties. $J$ Med Chem. 2010;53(13):4927-4937.

154. Çolak AT, Çolak F, Yeşilel OZ, Büyükgüngör O. Synthesis, spectroscopic, thermal, voltammetric studies and biological activity of crystalline complexes of pyridine-2,6-dicarboxylic acid and 8-hydroxyquinoline. J Mol Struct. 2009;936(1-3):67-74.

155. Czapski G, Goldstein S. Requirements for SOD mimics operating in vitro to work also in vivo. Free Radic Res Commun. 1991;12-13(Pt 1): 167-171.

156. Wang Y, Yang ZY, Wang BD. Synthesis, characterization and antioxidative activity of cobalt(II), nickel(II) and iron(II) Schiff base complexes. Transit Metal Chem. 2005;30:879-883.

157. Suksrichavalit T, Prachayasittikul S, Nantasenamat C, IsarankuraNa-Ayudhya C, Prachayasittikul V. Copper complexes of pyridine derivatives with superoxide scavenging and antimicrobial activities. Eur J Med Chem. 2009;44(8):3259-3265. 
158. Suksrichavalit T, Prachayasittikul S, Piacham T, Isarankura-NaAyudhya C, Nantasenamat C, Prachayasittikul V. Copper complexes of nicotinic-aromatic carboxylic acids as superoxide dismutase mimetics. Molecules. 2008;13(12):3040-3056.

159. MacMicking J, Xie QW, Nathan C. Nitric oxide and macrophage function. Annu Rev Immunol. 1997;15:323-350.

160. Kim YH, Woo KJ, Lim JH, et al. 8-Hydroxyquinoline inhibits iNOS expression and nitric oxide production by down-regulating LPSinduced activity of NF-kappaB and C/EBPbeta in Raw 264.7 cells. Biochem Biophys Res Commun. 2005;329(2):591-597.

161. Alderton WK, Cooper CE, Knowles RG. Nitric oxide synthases: structure, function and inhibition. Biochem J. 2001;357(Pt 3):593-615.

162. Rao KM. Molecular mechanisms regulating iNOS expression in various cell types. J Toxicol Environ Health B Crit Rev. 2000;3(1):27-58.

163. Lee AK, Sung SH, Kim YC, Kim SG. Inhibition of lipopolysaccharideinducible nitric oxide synthase, TNF-alpha and COX-2 expression by sauchinone effects on I-kappaBalpha phosphorylation, C/EBP and AP-1 activation. Br J Pharmacol. 2003;139(1):11-20.

164. Xie QW, Kashiwabara Y, Nathan C. Role of transcription factor NF-kappa B/Rel in induction of nitric oxide synthase. J Biol Chem. 1994;269(7):4705-4708.

165. Hu H, Shih R, Rothenberg S, Schwartz BS. The epidemiology of lead toxicity in adults: measuring dose and consideration of other methodologic issues. Environ Health Perspect. 2007;115(3):455-462.

166. Kosnett MJ, Becker CE, Osterloh JD, Kelly TJ, Pasta DJ. Factors influencing bone lead concentration in a suburban community assessed by noninvasive K x-ray fluorescence. JAMA. 1994;271(3):197-203.

167. Menke A, Muntner P, Batuman V, Silbergeld EK, Guallar E. Blood lead below $0.48 \mathrm{micromol} / \mathrm{L}(10 \mathrm{microg} / \mathrm{dL})$ and mortality among US adults. Circulation. 2006;114(13):1388-1394.

168. Shih RA, Hu H, Weisskopf MG, Schwartz BS. Cumulative lead dose and cognitive function in adults: a review of studies that measured both blood lead and bone lead. Environ Health Perspect. 2007;115(3): 483-492.

169. Weisskopf MG, Proctor SP, Wright RO, et al. Cumulative lead exposure and cognitive performance among elderly men. Epidemiology. 2007;18(1):59-66.

170. Bergdahl IA, Grubb A, Schütz A, et al. Lead binding to deltaaminolevulinic acid dehydratase (ALAD) in human erythrocytes. Pharmacol Toxicol. 1997;81(4):153-158.

171. Paglia DE, Valentine WN, Dahlgren JG. Effects of low-level lead exposure on pyrimidine $5^{\prime}$-nucleotidase and other erythrocyte enzymes. Possible role of pyrimidine $5^{\prime}$-nucleotidase in the pathogenesis of lead-induced anemia. J Clin Invest. 1975;56(5):1164-1169.

172. Boas FE, Forman L, Beutler E. Phosphatidylserine exposure and red cell viability in red cell aging and in hemolytic anemia. Proc Nat Acad Sci US A. 1998;95(6):3077-3081.

173. Chiu D, Lubin B, Roelofsen B, van Deenen LL. Sickled erythrocytes accelerate clotting in vitro: an effect of abnormal membrane lipid asymmetry. Blood. 1981;58(2):398-401.

174. Shin JH, Lim KM, Noh JY, et al. Lead-induced procoagulant activation of erythrocytes through phosphatidylserine exposure may lead to thrombotic diseases. Chem Res Toxicol. 2007;20(1):38-43.
175. Rogan WJ, Dietrich KN, Ware JH, et al; Treatment of Lead-Exposed Children Trial Group. The effect of chelation therapy with succimer on neuropsychological development in children exposed to lead. $N$ Eng J Med. 2001;344(19):1421-1426.

176. Hamidinia SA, Erdahl WL, Chapman CJ, Steinbaugh GE, Taylor RW, Pfeiffer DR. Monensin improves the effectiveness of meso-dimercaptosuccinate when used to treat lead intoxication in rats. Environ Health Perspect. 2006;114(4):484-493.

177. Sakai T, Yanagihara S, Kunugi Y, Ushio K. Mechanisms of ALA-D inhibition by lead and of its restoration by zinc and dithiothreitol. Br J Ind Med. 1983;40(1):61-66.

178. Meredith PA, Moore MR, Goldberg A. Effects of aluminium, lead and zinc on delta-aminolevulinic acid dehydratase. Enzyme. 1977;22(1): 22-27.

179. Jin S, Cheng Y, Reid S, Li M, Wang B. Carbohydrate recognition by boronolectins, small molecules, and lectins. Med Res Rev. 2010;30(2): 171-257.

180. Phillips MD, Fyles TM, Barwell NP, James TD. Carbohydrate sensing using a fluorescent molecular tweezer. Chem Commun (Camb). 2009;43:6557-6559.

181. Ardá A, Venturi C, Nativi C, et al. A chiral pyrrolic tripodal receptor enantioselectively recognizes beta-mannose and beta-mannosides. Chemistry. 2010;16(2):414-418.

182. Davis AP. Synthetic lectins. Org Biomol Chem. 2009;7(18): 3629-3638.

183. Mazik M, Geffert C. 8-Hydroxyquinoline as a building block for artificial receptors: binding preferences in the recognition of glycopyranosides. Org Biomol Chem. 2011;9(7):2319-2326.

184. Melnik B, John SM, Schmitz G. Over-stimulation of insulin/IGF-1 signaling by western diet may promote diseases of civilization: lessons learnt from Laron syndrome. Nutr Metab (Lond). 2011;8(1):41.

185. Cheng Z, White MF. Targeting forkhead box O1 from the concept to metabolic diseases: lessons from mouse models. Antioxid Redox Signal. 2011;14(4):649-661.

186. Salih DA, Brunet A. FoxO transcription factors in the maintenance of cellular homeostasis during aging. Curr Opin Cell Biol. 2008;20(2): 126-136.

187. Buteau J, Accili D. Regulation of pancreatic beta-cell function by the forkhead protein FoxO1. Diabetes Obes Metab. 2007;9(Suppl 2):140-146.

188. Rains JL, Jain SK. Oxidative stress, insulin signaling, and diabetes. Free Radic Biol Med. 2011;50(5):567-575.

189. Cameron AR, Anil S, Sutherland E, Harthill J, Rena G. Zinc-dependent effects of small molecules on the insulin-sensitive transcription factor FOXO1a and gluconeogenic genes. Metallomics. 2010;2(3): 195-203.

190. Cameron AR, Wallace K, Logie L, et al. The anti-neurodegenerative agent clioquinol regulates the transcription factor FOXO1a. Biochem J. 2012;443(1):57-64.

191. Kitamura T, Nakae J, Kitamura Y, et al. The forkhead transcription factor Foxo1 links insulin signaling to $\mathrm{Pdx} 1$ regulation of pancreatic beta cell growth. J Clin Invest. 2002;110(12):1839-1847.
Drug Design, Development and Therapy

\section{Publish your work in this journal}

Drug Design, Development and Therapy is an international, peerreviewed open-access journal that spans the spectrum of drug design and development through to clinical applications. Clinical outcomes, patient safety, and programs for the development and effective, safe, and sustained use of medicines are a feature of the journal, which

\section{Dovepress}

has also been accepted for indexing on PubMed Central. The manuscript management system is completely online and includes a very quick and fair peer-review system, which is all easy to use. Visit http://www.dovepress.com/testimonials.php to read real quotes from published authors. 